\section{(D) Check for updates}

Cite this: Org. Chem. Front., 2021, 8, 5531

Received 7th May 2021,

Accepted 27th May 2021

DOI: 10.1039/d1qo00699a

rsc.li/frontiers-organic

\title{
Direct synthetic routes to functionalised crown ethers
}

\author{
Federico Nicoli, (DD a,b Massimo Baroncini, (DD ${ }^{\text {a,c }}$ Serena Silvi, (D) ${ }^{\text {a,d }}$ Jessica Groppi (D) *a \\ and Alberto Credi iD *a,b
}

Crown ethers are macrocyclic hosts that can complex a wide range of inorganic and organic cations as well as neutral guest species. Their widespread utilization in several areas of fundamental and applied chemistry strongly relies on strategies for their functionalisation, in order to obtain compounds that could carry out multiple functions and could be incorporated in sophisticated systems. Although functionalised crown ethers are normally synthesised by templated macrocyclisation using appropriately substituted starting materials, the direct addition of functional groups onto a pre-formed macrocyclic framework is a valuable yet underexplored alternative. Here we review the methodologies for the direct functionalisation of aliphatic and aromatic crown ethers sporadically reported in the literature over a period of four decades. The general approach for the introduction of moieties on aliphatic crown ethers involves a radical mediated cross dehydrogenative coupling initiated either by photochemical or thermal/chemical activation, while aromatic crown ethers are commonly derivatised via electrophilic aromatic substitution. Direct functionalization routes can reduce synthetic effort, allow the later modification of crown etherbased architectures, and disclose new ways to exploit these versatile macrocycles in contemporary supramolecular science and technology.

\section{Introduction}

Crown ethers (CE), in their most common form, are macrocyclic oligomers of ethylene oxide characterised by selective binding abilities toward cationic and neutral species. Although cyclic polyethers had been known since the early $1900 \mathrm{~s},{ }^{1}$ Charles J. Pedersen was the first in 1967 to discover an efficient strategy to prepare macrocyclic polyethers, and to systematically study their binding properties towards metal cations. $^{2}$ Pedersen named "crown ethers" this new class of compounds, inspired by the appearance of the molecular models of the complexes formed with cations, in which the ether host seems to crown the metal guest (Fig. 1). ${ }^{3}$ His seminal work led Pedersen, along with Donald J. Cram and Jean-Marie Lehn, to receive the Nobel Prize in Chemistry in 1987 , for "the development and use of molecules with structure-specific interactions of high selectivity". ${ }^{3-5}$ CE have been

\footnotetext{
${ }^{a}$ CLAN-Center for Light Activated Nanostructures, Istituto ISOF-CNR via Gobetti 101, 40129 Bologna, Italy.E-mail: alberto.credi@unibo.it, jessica.groppi@unibo.it ${ }^{b}$ Dipartimento di Chimica Industriale "Toso Montanari", Università di Bologna, viale del Risorgimento 4, 40136 Bologna, Italy

${ }^{c}$ Dipartimento di Scienze e Tecnologie Agro-alimentari, Università di Bologna, viale Fanin 44, 40127 Bologna, Italy

${ }^{d}$ Dipartimento di Chimica "G. Ciamician", Università di Bologna, via Selmi 2, 40126 Bologna, Italy
}

instrumental for the advancement of the field of supramolecular chemistry ${ }^{6,7}$ and have found widespread application, ${ }^{8}$ so much so that currently many of them are commercially available.

CE can be divided into two groups: aliphatic and aromatic (Fig. 2). The most common aliphatic CE are cyclic oligomers of ethylene oxide, in which from four to a maximum of ten -

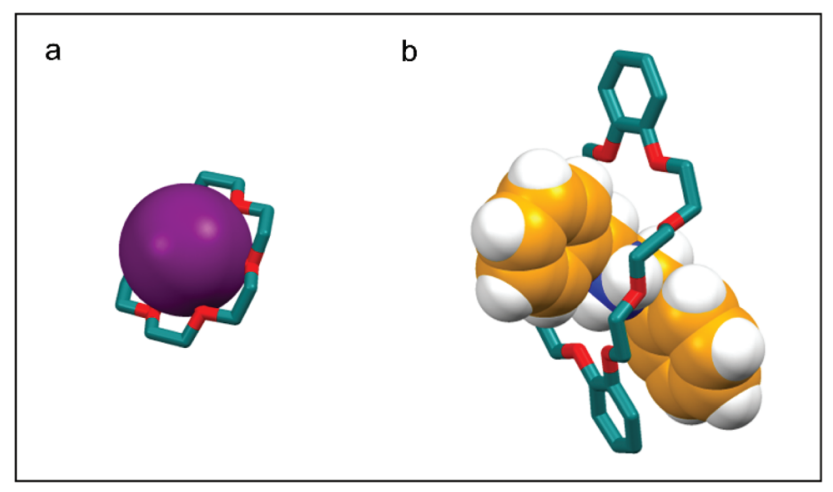

Fig. 1 Representative examples of crown ether-based supramolecular elements. Crystal structure of: (a) the supramolecular complex formed between the potassium cation and 18-crown-6; (b) the pseudorotaxane consisting of a dibenzylammonium axle threaded through dibenzo-24crown-8. 

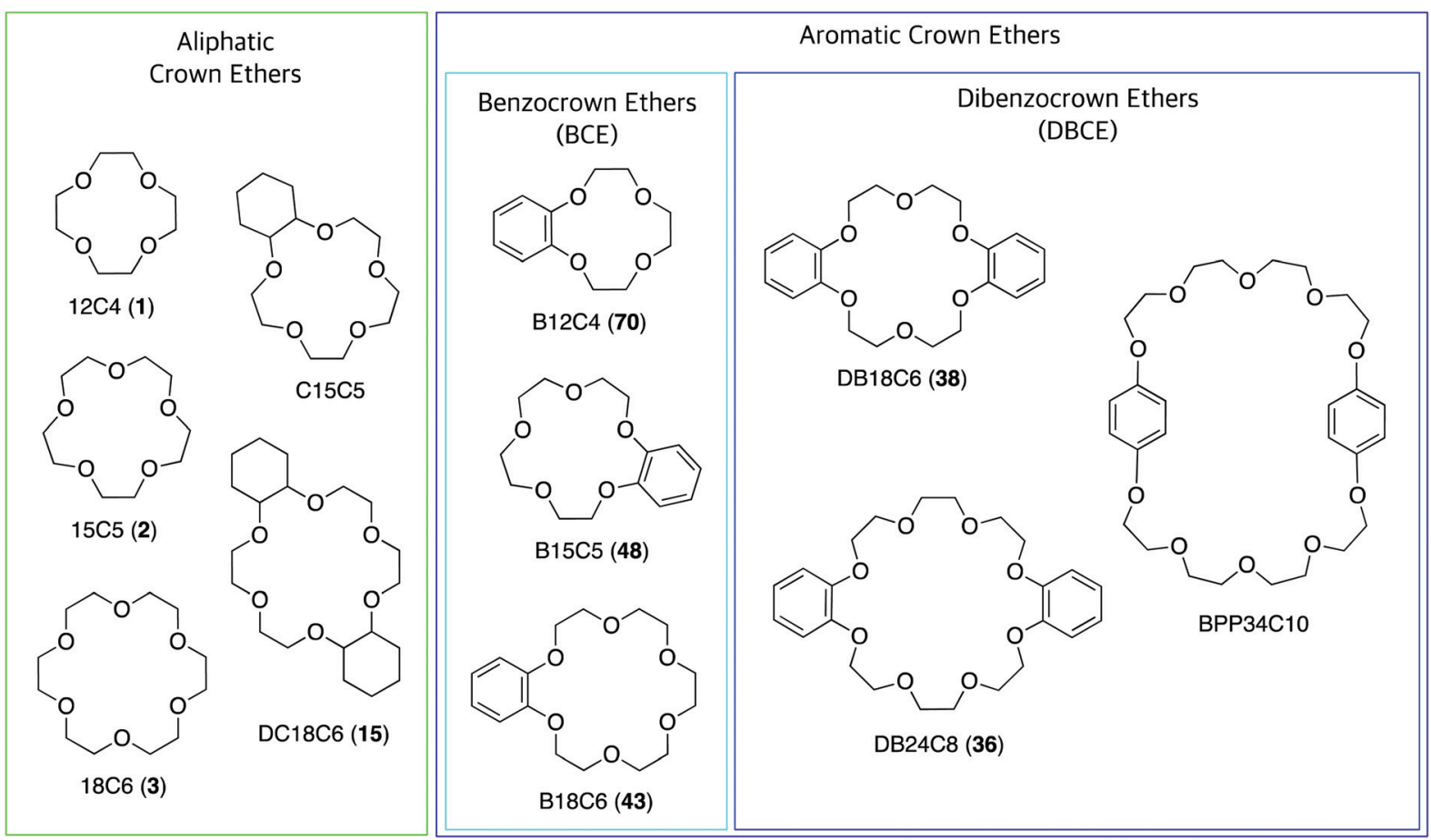

Fig. 2 Structure of commonly used crown ethers, most of which are commercially available. The numbers in parentheses are the compound labels used in this article.

$\left(\mathrm{CH}_{2} \mathrm{CH}_{2} \mathrm{O}\right)$ - repeating units are linked together; one or more ethylene groups of the macrocycle may be part of an aliphatic moiety such as cyclohexyl. Aromatic CE are characterised by the presence of endocyclic aromatic rings in their structure. Although a wide range of aromatic moieties has been incorporated in aromatic $\mathrm{CE},{ }^{9}$ the benzene ring represents by far the most common instance, giving rise to benzocrown (BCE) and dibenzocrown (DBCE) ethers. Crown ethers are conventionally indicated as $x$-crown-y (abbreviated $x \mathrm{C} y$ ) in which $x$ is the number of atoms in the macrocyclic cavity and $y$ is the number of these atoms that are oxygen. Thus, 18-crown-6, or 18C6, is a crown ether with a cavity of 18 atoms, 6 of which are oxygen.

The peculiar characteristics of CEs originate from the graceful interaction between the chemically stable and conformationally flexible ethylene units, and the nucleophilic oxygen atoms symmetrically arranged around the ring. This combi-

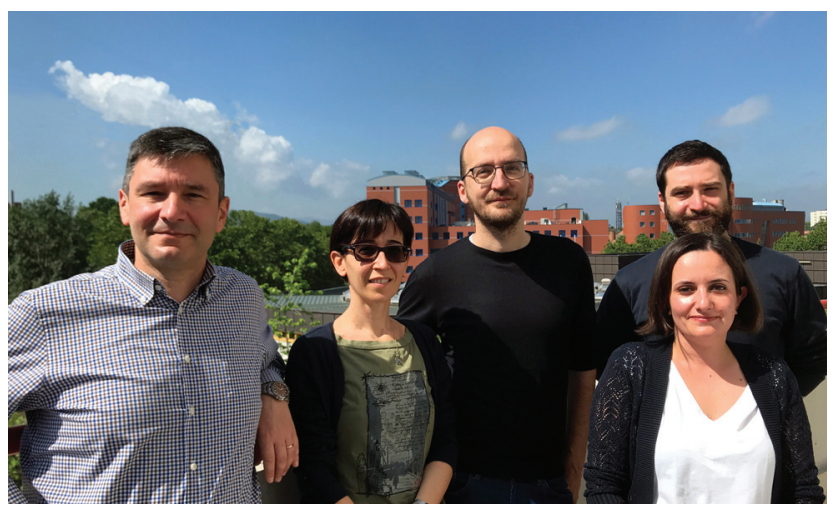

From left to right: Alberto Credi, Serena Silvi, Massimo Baroncini, Jessica Groppi and Federico Nicoli

Federico Nicoli received his Msc in chemistry from Sapienza University in Rome. Since 2018 he has been a PhD student in the Clan laboratory, engaged in the synthesis and characterization of multicomponent molecular species.
Massimo Baroncini is assistant professor at the University of Bologna and Clan member. His research, focused on the synthesis and investigation of supramolecular systems with tailored physicochemical functionalities, has led to the publication of 60 contributions.

Serena Silvi is associate professor of chemistry at the University of Bologna and Clan member. She has coauthored more than 100 articles, reviews and book chapters on the photochemical and electrochemical properties of complex (supra)molecular systems.

Jessica Groppi received her PhD in Chemistry from Queen Mary University in London and she has been a postdoctoral researcher at Clan since 2016. Her research deals with the development of functional mechanically interlocked molecules.

Alberto Credi is professor of chemistry at the University of Bologna, CNR associate, and director of the Center for Light Activated Nanostructures (Clan). He has published more than 300 scientific papers and 5 books on supramolecular systems and materials, and he is the PI of an ERC Advanced Grant on photoactive molecular motors. 
nation generates an electron rich cavity able to accommodate suitable guests, as well as to endow the compounds with a relatively amphiphilic nature. ${ }^{3,10}$ Early complexation studies were focused on the interaction between $\mathrm{CE}$ and metal ions: it was demonstrated that the process is driven by several factors, including the relative sizes of the ether host and the cationic guest, the charge of the cation, the number and location of the oxygen atoms, the steric hindrance on the ring, and the competition by the solvent. .,3,6,7 $^{2}$

Indeed, $\mathrm{CE}$ are able to selectively bind alkali and alkaline earth ions (Fig. 1a), forming complexes which, owing to the lipophilic character, are soluble in non-polar solvents, thus acting as carriers of the charged species. For this reason, CE have been extensively used in phase transfer catalysis ${ }^{11}$ and ion extraction; ${ }^{12}$ more recently, they have been exploited as ion translocators and as components for synthetic channels through lipidic membranes. ${ }^{13}$ In the last three decades, it has been demonstrated that the complexing ability of CE is not limited to metal cations, as CE can generate stable supramolecular complexes with a wide variety of organic guests in aprotic solvents (Fig. 1b). Arenediazonium salts, which are readily complexed and stabilised by $18 \mathrm{C} 6$ and $21 \mathrm{C} 7$, were one of the first reported examples of non-metallic guests. ${ }^{14}$ Aromatic CEs, by virtue of their $\pi$-electron rich aromatic groups, act as hosts for different $\pi$-electron poor guests such as bipyridinium, ${ }^{15}$ diazapyrenium, ${ }^{16}$ bis-(pyridinium)ethane, ${ }^{17}$ imidazolium, ${ }^{18}$ and triazolium. ${ }^{19}$ Besides electrostatic effects, both donor-acceptor $\pi-\pi$ interactions and strong hydrogen bonds contribute to the formation and stability of these complexes.

The complexes of primary alkylammonium ions $\left(\mathrm{RNH}_{3}{ }^{+}\right)$ with DB18C6 have been extensively studied. The host and guest interact in a face-to-face orientation, with the formation of three alternating hydrogen bonds between the oxygen atoms of the macrocycle and the ammonium group, forming very stable supramolecular entities. A consequence of this binding motif is that the stability of complexes formed with secondary and tertiary ammonium ions is much lower. ${ }^{20}$

Stoddart and co-workers first demonstrated that crown ethers with a larger cavity, such as DB24C8, form complexes with secondary alkylammonium ions in which the cation "pierces through" the cavity of the macrocycle (Fig. 1b). ${ }^{21}$ Secondary ammonium guests designed to have an axle-type structure are therefore able to thread appropriately sized crown ethers $^{22}$ to generate pseudorotaxanes which are not only interesting per $s e{ }^{23}$ but also useful supramolecular precursors to mechanically interlocked molecules (MIMs). CE, given their versatility as host molecules, have nowadays become a staple in the construction of MIMs and have been included in the design of hundreds of rotaxane architectures and catenane topologies. ${ }^{24}$ A direct consequence of the inclusion of $\mathrm{CE}$ as components of MIMs, is their application in the development of artificial molecular machines: ${ }^{24-26} \mathrm{pH}$, redox, or light activated mechanical switches ${ }^{27}$ and molecular pumps ${ }^{28}$ are just a few examples of molecular devices incorporating CE. The interest in functionalising $\mathrm{CE}$ has grown in parallel to the number of their areas of application. Crown ethers have been deriva- tised in order to couple the ability to form complexes with other functions such as catalysis, ${ }^{29}$ self-assembly $^{30}$ and sensing, ${ }^{31}$ and to be introduced in dendrimers, ${ }^{32}$ polymers, ${ }^{33}$ and covalent ${ }^{34}$ or metal organic frameworks. ${ }^{35}$ In the field of MIMs, functionalised CE have been used for the construction of interlocked polymers ${ }^{36}$ and higher order structures, ${ }^{37}$ molecular transporters, ${ }^{38}$ mechanically planar chiral rotaxanes, ${ }^{39}$ and dynamic crystalline materials. ${ }^{40}$

Despite the extensive application of functionalised CE and the astounding number of reports dealing with the properties and uses of this class of macrocycles, to our best knowledge the only review article on the synthesis of modified CE was published by Bradshaw et al. in 1980. ${ }^{41}$ Homberg et al. recently described in a minireview an alternative approach to templated ring closure for the synthesis of chiral polyether macrocycles. ${ }^{42}$ To the present day, only one publication by Pluzhnik-Gladyr describes methodologies for the direct halogenation of CE. ${ }^{43}$

This review will focus on direct synthetic routes to functionalised CE, encompassing publications until April 2021; the literature cited in previous reviews will not be included, unless it is necessary to better assess newer protocols. After a brief excursus regarding the main synthetic strategies for the preparation of functionalised crown ethers and their pro and cons, the discussion will move to direct functionalisation protocols and it will be organized according to the class of the CE substrate, either aliphatic or aromatic.

\section{Synthetic approaches to functionalised crown ethers}

The synthesis of functionalised crown ethers is performed following two main approaches: templated macrocyclisation, using pre-functionalised starting materials, or direct functionalisation of previously formed CE. Although templated macrocyclisation is the most used approach for the synthesis of functionalised CE, the introduction of substituents on preformed macrocycles represents a valid and, under some aspects, superior alternative. First of all, direct functionalisation routes are obviously the only option available when the $\mathrm{CE}$ to be functionalised is irreversibly embedded in a more extended architecture (e.g., a MIM). Hence, identifying procedures to perform selective reactions on $\mathrm{CE}$ is important to enable the modification of multicomponent species via postsynthetic pathways.

The protocols for the synthesis and purification of nonfunctionalised crown ethers have been optimized for large scale production, and a number of CE are currently commercially available at reasonable prices. Therefore, the direct functionalisation of a purchased macrocycle may drastically reduce the synthetic effort necessary to prepare ad hoc CE. This is particularly true for aliphatic $\mathrm{CE}$, for which the preparation of the derivatised precursors usually requires a significant number of steps, potentially resulting in a waste of time and resources compared to a one-step direct functionalisation. Moreover, in templated approaches, the introduced functional groups must 
be very stable under the macrocyclisation reaction conditions. Specifically, they must be able to withstand basic conditions and heating, and they must be inert towards nucleophilic addition as well as not being nucleophiles themselves; if this is not the case, parasite processes will likely lead to low yields and challenging purification procedures. This stringent limitation is clearly overcome by performing the functionalisation directly as the final step.

The principal limitation of direct approaches is indeed the lack of efficient, rigorously described and verified protocols and procedures. For example, direct reactions for mono-functionalisation of DBCE are characterised by poor yields, while those for bis-functionalisation suffer from scarce regioselectivity. Another drawback of direct functionalisation protocols is that an excess of the starting CE (or CE-containing substrate) must usually be employed to reach high yields of the final product; in most instances, however, the unreacted material can be recovered during purification. Surely, albeit direct functionalisation approaches are still underexplored, they can represent an advantageous and expedient synthetic strategy that deserves to be considered while confronting challenging CE-based synthetic targets.

Templated strategies rely on the size complementarity between the cavity of the target macrocycle and an added metal cation. The latter acts as a template by pre-organising the polyether chain precursor into the correct conformation required for efficient cyclisation, hence minimising the formation of polymeric side products. ${ }^{7,10}$ Thus, $\mathrm{Li}^{+}$templates the macrocyclisation of 12-membered CE, whereas $\mathrm{Na}^{+}, \mathrm{K}^{+}$and $\mathrm{Cs}^{+}$ favour 15-, 18- and 24-membered cycles, respectively. ${ }^{44-47}$

Aliphatic CE can be obtained either by closure of the ether macrocycle by nucleophilic addition of a functionalised diol to an n-ethyleneglycol-ditosylate (Scheme $1 \mathrm{a}$, top) ${ }^{44}$ or by a twostep procedure involving the reaction between an n-ethyleneglycol and a derivatised epoxide to produce the open functionalised $(n+1)$-ethyleneglycol chain. The latter is then converted to the final crown ether via a one-pot tosylation-macrocyclisation reaction (Scheme 1a, bottom). ${ }^{45}$ The yield of the isolated products could vary significantly according to the final ring size and the nature of the functional group, ranging from $12 \%$ to $72 \%$.

Templated macrocyclisation represents the go-to approach for the synthesis of BCE and DBCE presenting functional groups on the aromatic portion of their structure. In a typical procedure, a functionalised catechol is reacted with either an n-ethyleneglycol-ditosylate (or di-halogen) chain, to obtain BCE (Scheme 1b, top), ${ }^{46}$ or with a benzo-di-n-ethyleneglycolditosylate precursor, in the case of $\mathrm{DBCE}^{47}$ (Scheme $1 \mathrm{~b}$, bottom). Aromatic CE are routinely obtained in $40 \%-50 \%$ yield following such synthetic routes.

The methodologies for direct functionalisation will be thoroughly discussed in the upcoming sections of this review. In brief, functional groups can be introduced on aliphatic $\mathrm{CE}$ mainly via radical-mediated cross dehydrogenative coupling (CDC), while aromatic CE are generally functionalised via electrophilic substitution reactions of the aromatic moieties.
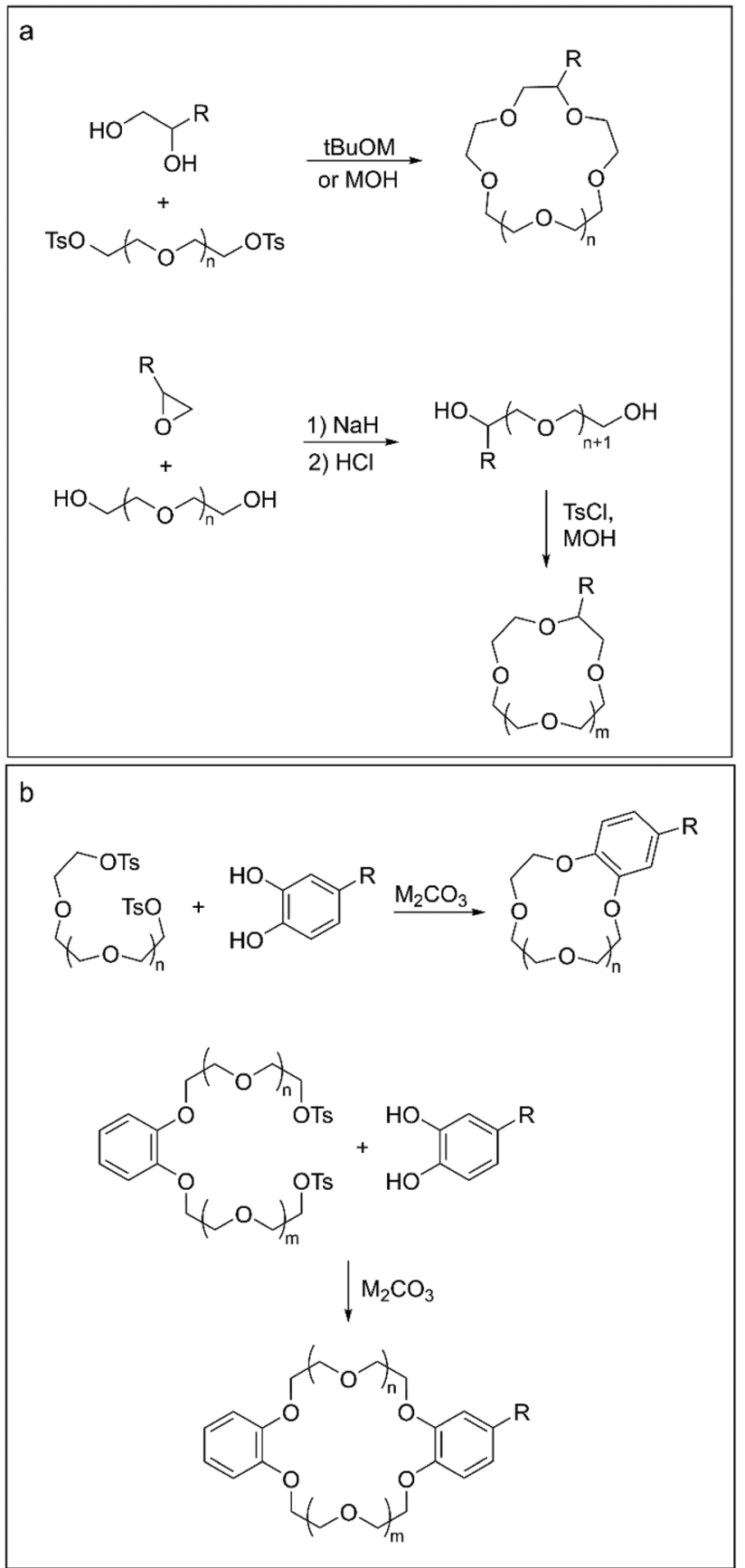

Scheme 1 Methodologies for the templated synthesis of functionalised aliphatic (a) and aromatic (b) crown ethers.

\section{Methodologies for direct functionalisation}

\subsection{Aliphatic crown ethers}

As introduced in the previous paragraph, most of the literature describing the direct functionalisation of aliphatic $\mathrm{CE}$ relies on the use of CDC for the introduction of a variety of functional groups: the selective oxidation of the $\alpha-\mathrm{C}\left(\mathrm{sp}^{3}\right)-\mathrm{H}$ bond to $\alpha-\mathrm{C}\left(\mathrm{sp}^{3}\right)-\mathrm{X}(\mathrm{X}=\mathrm{C}, \mathrm{N}, \mathrm{F})$ bond is achieved via radical inter- 
mediate mechanism. ${ }^{48}$ The process can be divided in three distinct steps: (I) generation of an electrophilic radical; (II) hydrogen abstraction from the CE by the electrophilic radical, with formation of a radical at the electron-rich $\alpha$-carbon; (III) reaction of the radical with the coupling partner to yield the functionalised crown (Scheme 2).

The routes for direct functionalisation of aliphatic CE can be divided in two groups, according to the method used for the generation of the electrophilic radical (step I). As the latter can be produced by either photochemical or thermal/chemical activation, this section will be organised accordingly. Peculiarities will be dealt with in due course, but some general remarks can be made. All the examples found report monofunctionalisation, although a large excess of the starting CE is usually needed. Reactions are normally performed under inert atmosphere and the purification of the derivatives is typically straightforward, achieved either by fractional distillation or chromatography. Finally, higher yields are reported for procedures that rely on photochemical radical generation compared to thermal/chemical one. The implications related to the generation of one or more chiral centres on the crown ether upon introduction of functional groups are frequently overlooked. Indeed, the functionalization of aliphatic CE leads to the formation of enantiomers, or diastereomeric pairs if a chiral centre is also present on the grafted functional group. Although such stereoisomers could be separated and might exhibit different recognition properties, they are usually isolated and characterized as mixtures (e.g. racemates).

3.1.1. Direct functionalisation by photochemical activation. One of the earliest examples of direct functionalisation of aliphatic CEs is represented by the photochemical derivatisation of 18-crown-6 (3) with alkyl aryl ketones reported by Tada et al. ${ }^{49}$ Irradiation with a $\mathrm{Hg}$ lamp of a 1:1 mixture of 3 and a ketone for several hours produced the corresponding mono-functionalised derivatives in yields comprised between $7 \%$ and $21 \%$, according to the nature of the $\mathrm{R}$ group present on the keto moiety. It is interesting to note that higher yields were obtained for those ketones able to generate complexes with 3, i.e. $\mathbf{4 b}$ and $\mathbf{4 e}$ (Scheme 3). Similarly, aliphatic CE were directly functionalised with 1,4-benzoquinones by photoirradiation. $^{50}$

More recently, Kamijo et al. exploited the ability of photochemically generated oxyl radicals to abstract a hydrogen atom by homolytic $\mathrm{C}-\mathrm{H}$ bond cleavage, to develop a general methodology for the conversion of electron-rich $\mathrm{C}\left(\mathrm{sp}^{3}\right)-\mathrm{H}$ into $\mathrm{C}\left(\mathrm{sp}^{3}\right)-$

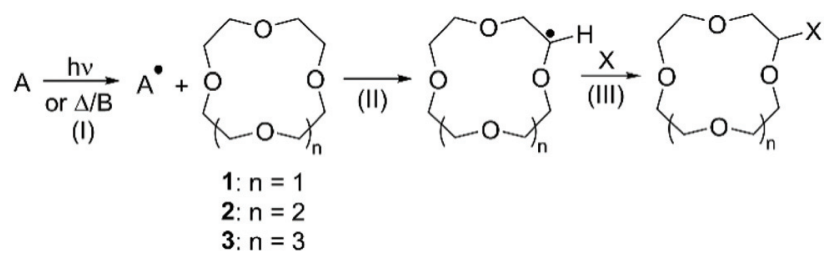

Scheme 2 Functionalisation of aliphatic crown ethers via cross dehydrogenative coupling (CDC).

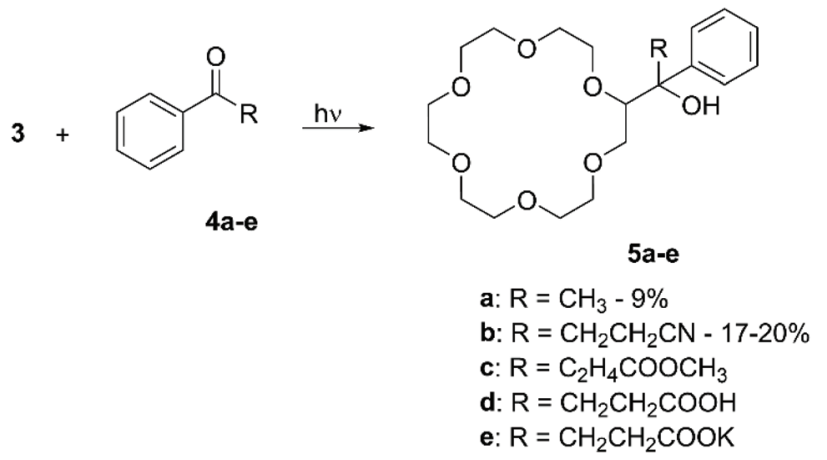

Scheme 3 Photochemical functionalisation of $18 C 6$ (3) with alkyl-arylketones.

C bonds. In this instance the ketone only acts as a photosensitiser in the process and the coupling partner is added as a tosyl derivative. Such an approach (Scheme 4) allowed to introduce cyano, ${ }^{51}$ alkynyl, ${ }^{52}$ alkenyl ${ }^{53}$ and aldoxime (as formyl precursor $^{54}$ functional groups on alkanes, benzylic compounds, ethers, alcohols and amines, generating derivatives suitable for conversion to synthetically relevant synthons. 15-crown-5 (2) was included in the substrate scope: irradiation with a $\mathrm{Hg}$ lamp of a mixture containing an excess of 2 , the ketone (1 equiv.) and the coupling partner (1 equiv.) at room temperature for periods that depend on the coupling partner (Table 1)

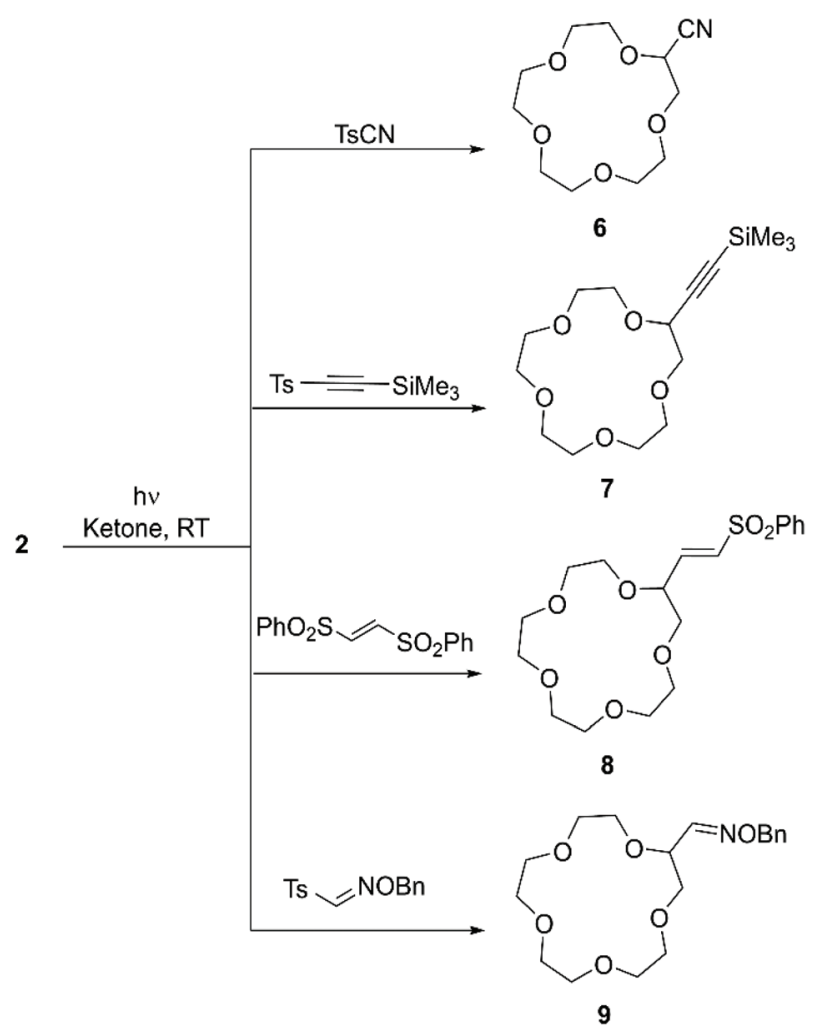

Scheme 4 Functional groups introduced on 15 C5 (2) according to the methodology reported by Kamijo et al. 
Table 1 Reaction conditions reported by Kamijo et al

\begin{tabular}{llllll}
\hline Product & Equiv. of 2 & Ketone & Solvent & $t(\mathrm{~h})$ & Yield (\%) $)^{\text {ref }}$ \\
\hline $\mathbf{6}$ & 8 & $\mathrm{Ph}_{2} \mathrm{CO}$ & $\mathrm{CH}_{3} \mathrm{CN}$ & 3 & $84^{51}$ \\
7 & 8 & $\mathrm{Ph}_{2} \mathrm{CO}$ & $t$ - $\mathrm{BuOH}$ & 1 & $82^{52}$ \\
$\mathbf{8}$ & 5 & $\mathrm{Ph}_{2} \mathrm{CO}$ & $\mathrm{CH}_{3} \mathrm{CN}$ & 5 & $71^{53}$ \\
$\mathbf{9}$ & 8 & $4-\mathrm{BzPy}$ & $\mathrm{CH}_{2} \mathrm{Cl}_{2}$ & 24 & $58(89)^{a, 54}$
\end{tabular}

${ }^{a}$ Yield determined by ${ }^{1} \mathrm{H}$ NMR.

leads to mono-functionalisation in high yield, despite the presence of multiple reactive sites on the molecule (Scheme 4).

This work motivated Beniazza et al. to apply a similar approach to the mono-fluorination of cyclic ethers to obtain derivatives suitable for further modification by nucleophilic substitution. ${ }^{55}$ The optimised procedure, consisting of a twostep one-pot protocol, was applied to the functionalisation of 3 with benzyl alcohol. First, a $\mathrm{CHCl}_{3}$ solution containing 3 (1 equiv.), a catalytic amount of benzophenone $(2 \% \mathrm{~mol})$, and $N$-fluorobis(phenyl)sulfonimide (NFSI) (0.5 equiv.) as a fluorine source, is irradiated at $320-390 \mathrm{~nm}$ for 20 minutes at room temperature. This process generates a transient monofluorinated macrocycle (10) in $74 \%$ yield, which, by addition of benzyl alcohol in the second step of the reaction, undergoes nucleophilic substitution affording product 11 in 56\% yield (Scheme 5). The transient nature of the monofluorinated adduct was explained by the formation of sulfonimide acid as a side product, which catalyses fluoride elimination.

Compound $\mathbf{1 0}$ was also reported by Bower et al. ${ }^{56}$ In this work, a formally copper(III) fluoride complex (LCuF) performed both the hydrogen atom abstraction and radical capture roles. Upon mixing 3 and LCuF in a 8:1 ratio in dichloromethane, product 10 was obtained in $35 \%$ yield (Scheme 6). The reactivity of the monofluorinated crown ether, however, was not further investigated.

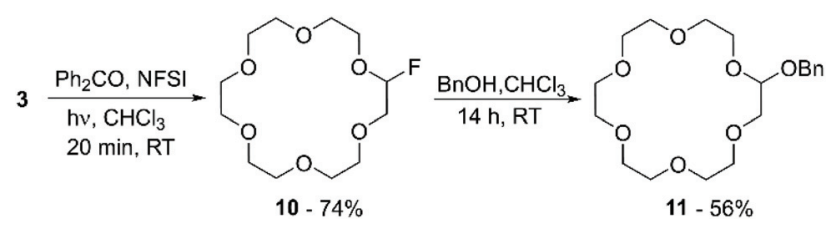

Scheme 5 Direct fluorination of $18 \mathrm{C} 6$ (3) and subsequent nucleophilic addition of benzyl alcohol.
3

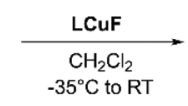

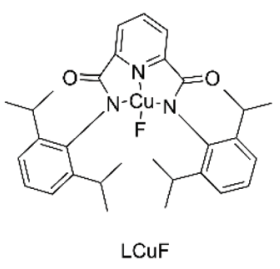

LCuF
Scheme 6 Direct fluorination of $18 C 6$ (3) using copper complex LCuF.
Previous to these recent studies on direct mono-fluorination, only per-fluorination of aliphatic $\mathrm{CE}$, including cyclohexano derivatives, had been carried out. ${ }^{57}$ The general procedure consisted in coating NaF with the chosen CE followed by exposing the solid mixture to a flow of fluorine gas in a cryogenic fluorination reactor under inert conditions (Scheme 7). The yields, that range between $12 \%$ and $35 \%$, were highly affected by several parameters, including fluorination conditions, the exposed surface area of the starting materials, as well as the initial purity of the reagents.

Risi et al. studied the photochemical coupling reaction between cyclic ethers and 4-methyl-1,2,4-triazoline-3,5-dione (4-MTAD).$^{58}$ The interest in such a specific functionalisation originates from the wide application of triazolinedione compounds in the fields of polymer science and click chemistry. ${ }^{59}$ Slow addition of 4-MTAD to an excess of CE 12-crown-4 (1), 2 or 3 under continuous laser irradiation at $\lambda=514.5 \mathrm{~nm}$ for several days, allowed for the formation of the corresponding $\alpha$-urazolyl derivatives. While in the case of 2 and 3 only the mono-functionalised product was isolated, for $\mathbf{1}$ also the bisurazoyl compound was obtained, for which the authors suggest either a symmetrical 1,3 or 1,7 substitution pattern according to the simple ${ }^{1} \mathrm{H}$ NMR and ${ }^{13} \mathrm{C}$ NMR spectra. (Scheme 8). The reaction mechanism, elucidated by ESR and computational calculations, involves the photoreduction of

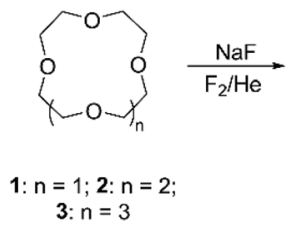

$3: n=3$

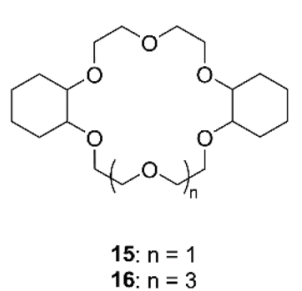

Scheme 7 Perfluorination of aliphatic crown ethers.

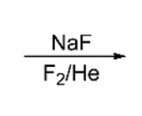

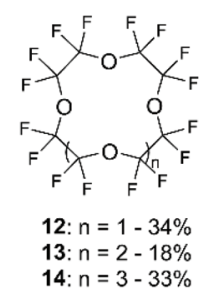

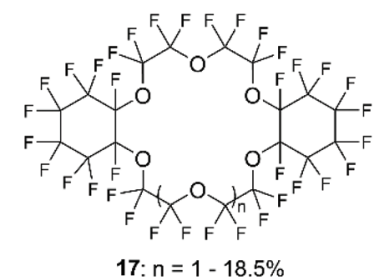

17: $n=1-18.5 \%$

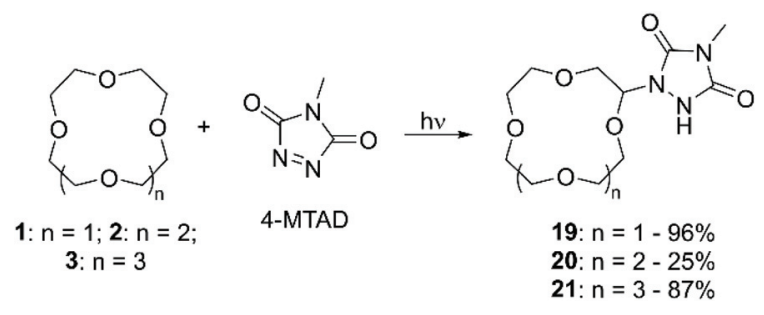

Scheme 8 Direct functionalisation of aliphatic crown ethers with 4-MTAD. 
4-MTAD to generate an urazolyl radical, followed by abstraction of a hydrogen atom from the polyether, and terminated in the coupling of the two intermediates. The reaction yields were excellent for products 19 and 21 while only 25\% was reported for compound 20; no further investigation was carried out to elucidate the reason behind the different reactivities of the three CE.

The covalent attachment of $\mathrm{CE}$ to [60]fullerene $\left(\mathrm{C}_{60}\right)$ has attracted attention for the photophysical and electrochemical properties of the resulting adducts and their potential applications in ion sensing and fluorescence switching devices. Tzirakis et al. first described the direct coupling of CE to $\mathrm{C}_{60}$, achieved photochemically using tetrabutylammonium decatungstate $\left[\left(\mathrm{nBu}_{4} \mathrm{~N}\right)_{4} \mathrm{~W}_{10} \mathrm{O}_{32}\right.$, TBADT $]$ as a photosensitiser (Scheme 9). ${ }^{60}$ The procedure, applied to the functionalisation of 1, 2 and 3, consisted in the irradiation with a xenon lamp of a mixture of the $\mathrm{CE}$ (100 equiv.), $\mathrm{C}_{60}$ (1 equiv.) and TBADT (0.5 equiv.) in $\mathrm{C}_{6} \mathrm{H}_{5} \mathrm{Cl} / \mathrm{CH}_{3} \mathrm{CN}(85: 15)$ for 20 minutes at $5-10{ }^{\circ} \mathrm{C}$. The yield was reported to be $50 \%$ for all the three isolated products. The authors also mentioned that the more common photosensitiser benzophenone was tested, but lower yields $(20 \%)$ were obtained despite the use of 100 equiv. of ketone.

In a recent publication, compound 23 was synthesised with the aim to study its reactivity toward sodium and bis(arene) chromium compounds. ${ }^{61}$ The coupling between $\mathrm{C}_{60}$ and 15C5 (2) was performed photochemically in presence of benzophenone at $50{ }^{\circ} \mathrm{C}$, irradiating a solution of the reagents in DCB for 5 hours. The reported yield was $30 \%$.

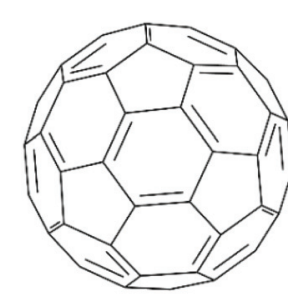

[60]Fullerene

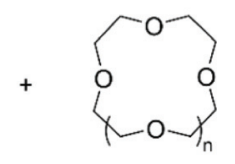

1: $\mathrm{n}=1 ; \mathbf{2}: \mathrm{n}=2$; 3: $n=3$
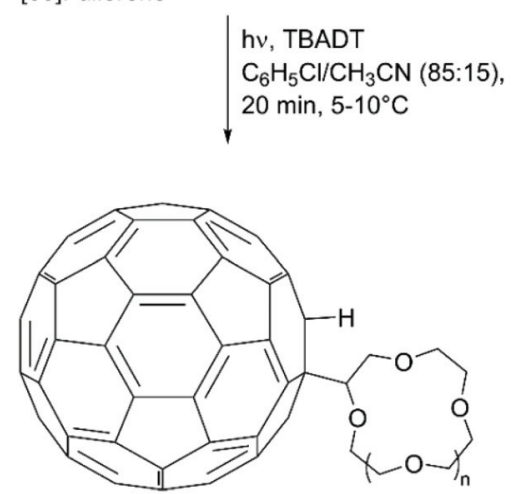

22: $\mathrm{n}=1-50 \%$

23: $\mathrm{n}=2-50 \%$

24: $n=3-50 \%$

Scheme 9 Photochemical functionalisation of [60]fullerene with aliphatic crown ethers.
3.1.2. Direct functionalisation by thermal/chemical activation. The optimisation of a route for the addition of CE to olefins was attempted by Zeleconok et al. ${ }^{62}$ The approach consisted in the treatment of crown ether 3 with di-t-butylperoxide (DTBP) at high temperature to generate a radical, that would then attack the double bond of the substrate, thus yielding the alkylated final product (Scheme 10). The fast mixing of the reaction components 3 : olefin: DTBP in 10:2:1 molar ratio led to very low conversion of $\mathbf{3}$ and formation of telomers, highlighting the poor control over the process. On the other hand, the slow addition of peroxide and olefin to a very large excess of 3 (3 : olefin : DTBP $=20: 2: 1$ ) led to a slight improvement of the yield, reaching values up to $30 \%$. Nonetheless, the methodology has been applied to the functionalisation of $\mathbf{1}, 2$ and 3 with allyl chloride for the introduction of 8-hydroxyquinoline $^{63}$ and to synthesise alkyl-CE for the development of antifungal agents. ${ }^{64}$

DTBP in presence of radical initiators was also used as a hydrogen abstractor in protocols for the functionalisation of $\mathrm{CE}$ with N-aromatic bases (Scheme 11). Early procedures relied on the use of metals such as Fe(II) and Ti(III) to generate the peroxyl radical, ${ }^{65}$ while in a recent more "green" approach DTBP was activated by photoirradiation with a higher control on the regioselection of the final products (Table 2). ${ }^{66}$ In all cases, functionalised CE were obtained in good yields.

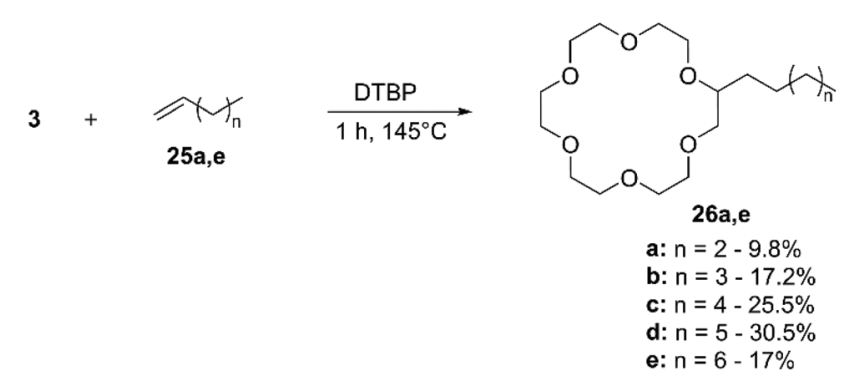

Scheme 10 Alkylation of $18 C 6$ (3) with chains of variable length.

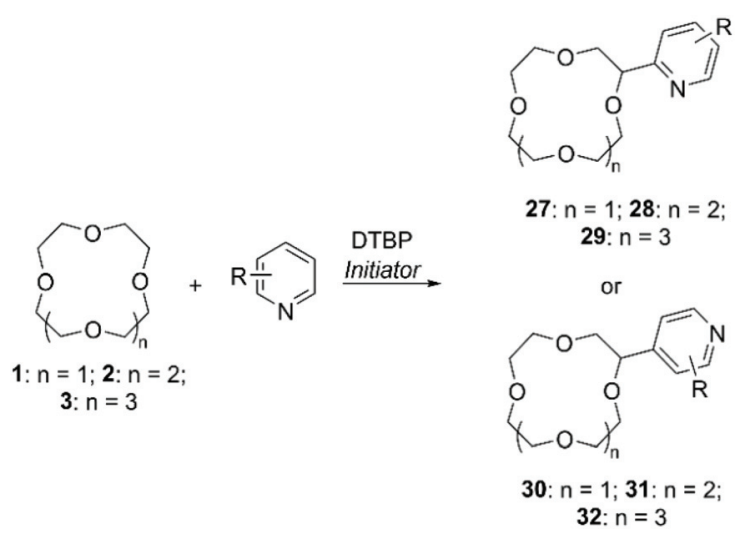

Scheme 11 Functionalisation of aliphatic crown ethers with aromatic bases. 
Table 2 Reaction conditions for the functionalisation of aliphatic crown ethers with aromatic bases

\begin{tabular}{|c|c|c|c|c|c|c|}
\hline $\mathrm{CE}$ & $\mathrm{N}$-aromatic base & Init. & Solv. & $t(\mathrm{~h})$ & $T\left({ }^{\circ} \mathrm{C}\right)$ & Yield (\%) [Prod $]^{\text {ref }}$ \\
\hline 3 & Quinoxaline & $\mathrm{TiCl}_{3}$ & $\mathrm{H}_{2} \mathrm{O}$ & - & RT & $-[29]^{65 b}$ \\
\hline 3 & 4-Methylquinoline & $\mathrm{TiCl}_{3}$ & $\mathrm{H}_{2} \mathrm{O}$ & - & $\mathrm{RT}$ & $-[29]^{65 b}$ \\
\hline 3 & Quinoline & $\mathrm{FeSO}_{4}$ & DMSO & 0.5 & $\mathrm{RT}$ & $20[\mathbf{1 9}]^{65 c} 30[\mathbf{3 2}]^{65 c}$ \\
\hline 3 & Quinoxaline & $\mathrm{FeSO}_{4}$ & DMSO & 0.5 & RT & $85[29]^{65 c}$ \\
\hline 2 & 2-Methylquinoline & $\mathrm{FeSO}_{4}$ & DMSO & 1 & RT & $65[31]^{65 d}$ \\
\hline 3 & 4-Methylquinoline & $\mathrm{h} \nu$ & EDC & 23 & 40 & $71[29]^{66}$ \\
\hline 2 & 4-Methylquinoline & $\mathrm{h} v$ & EDC & 23 & 40 & $61[28]^{66}$ \\
\hline 3 & Isoquinoline & $\mathrm{h} v$ & EDC & 23 & 40 & $68[29]^{66}$ \\
\hline 2 & Isoquinoline & $\mathrm{hv}$ & EDC & 23 & 40 & $61[28]^{66}$ \\
\hline
\end{tabular}

An alternative to peroxyl radicals for the direct attachment of $\mathrm{N}$-aromatic bases to $\mathrm{CE}$ is represented by N-hydroxysuccinimide (NHS)-mediated C $\alpha$-heteroarylation. ${ }^{67}$ The reaction consists in the formation of a reactive $\mathrm{N}$-radical form of NHS by oxidation with ammonium persulfate (APS); the generated radical carries out hydrogen abstraction on the ether, which in turn proceeds to attack the heteroaromatic base in a regioselective fashion (Scheme 12). Following this method, 1 was selectively introduced onto position 1 of isoquinoline to obtain compound $\mathbf{3 3}$ in $75 \%$ yield.

The serendipitous discovery that acetylenic triflones spontaneously react with THF at room temperature to afford the $\alpha$-alkynylated product in almost quantitative yields brought Fuchs et al. to establish a methodology which exploits the reactivity of the trifluoromethyl radical towards $\mathrm{C}-\mathrm{H}$ hydrogen abstraction for the introduction of alkyne functional group on several classes of compounds. ${ }^{68}$ Subsequently, the reaction was successfully applied for the direct alkynylation of $\mathbf{1}$ and $\mathbf{2}$ (Scheme 13). ${ }^{69}$ Heating an excess of CE and acetylenic triflone (1 equiv.) in $\mathrm{CH}_{3} \mathrm{CN}$ in presence of a catalytic amount of azobisisobutyronitrile (AIBN) $(20 \% \mathrm{~mol})$ as the radical initiator, led to the conversion to the corresponding mono-alkynylated product in good yields (Table 3 ).

\subsection{Aromatic crown ethers}

The optimisation of synthetic protocols for production upscaling and the straightforward access to functionalised catechols enabled the preparation of a large variety of aromatic CE characterised by a wide range of properties. Moreover, the ease

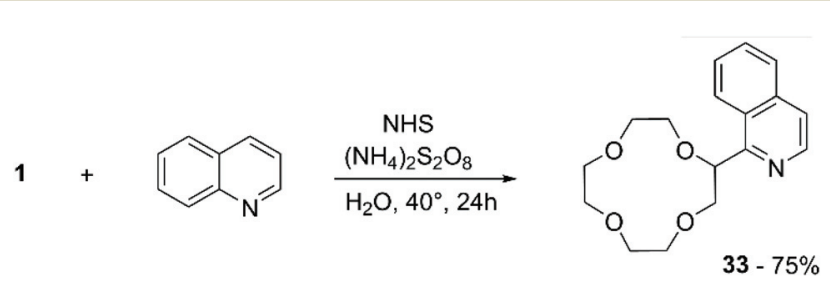

Scheme 12 NHS mediated functionalisation of $12 \mathrm{C} 4$ (1) with isoquinoline.

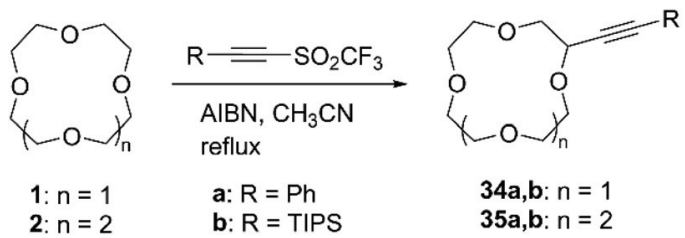

Scheme 13 Alkynylation of aliphatic crown ethers with acetylenic triflones.

Table 3 Reaction conditions for the functionalisation of aliphatic crown ethers with acetylenic triflones ${ }^{69}$

\begin{tabular}{llll}
\hline Product & CE equiv. & $t(\mathrm{~h})$ & Yield (\%) \\
\hline $\mathbf{3 4 a}$ & 10 & 3 & 70 \\
$\mathbf{3 4 b}$ & 5 & 6 & 70 \\
$\mathbf{3 5 a}$ & 10 & 2 & 80 \\
$\mathbf{3 5 b}$ & 5 & 5 & 70
\end{tabular}

of handling and the solubility in most organic solvents brought this class of crown ethers at the center of many basic and applied investigations. The direct functionalisation of BCE and DBCE is usually achieved by electrophilic substitution on the aromatic portion. Hence, this part of the review will be organised according to the introduced functional groups. Albeit procedures have been adapted from general methodologies used for the derivatisation of aromatic compounds, the outcome can be affected by electronic and steric effects related to ring size and conformation. The weak points of this approach are the lack of control on the number of groups introduced in the crown ether framework (specifically, monofunctionalised adducts are obtained in low yields, since bisfunctionalisation frequently proceeds in parallel) and, relatively to DBCE, poor regioselectivity (both syn and anti disubstituted products are obtained and their separation is not straightforward).

3.2.1. Functionalisation with halides. In 2016 PluzhnikGladyr published a review on halogenated $\mathrm{BCE}$, focusing on three main approaches for direct halogenation. ${ }^{43}$ The first one 
involves the use of molecular halogens. Such a technique is suitable for obtaining di-halogenated BCE and tetra-halogenated DBCE in good yields; the high reactivity of elemental halogen species however precludes the synthesis of monofunctionalised derivatives. The second methodology relies on N-halosuccinimides: while BCE can be easily halogenated with these reagents in aqueous media (the reaction can be catalysed by addition of acid), DBCE react only in organic solvents $\left(\mathrm{CHCl}_{3}\right.$ or $\left.\mathrm{CCl}_{4}\right)$ or in mixtures of ethanol and water. Finally, direct halogenation can be achieved using hypohalites in water. Because of solubility reasons, this approach can only be used for the halogenation of BCE. Interestingly, acidic conditions lead to the addition of multiple halogen atoms, while basic $\mathrm{pH}$ allows to control the reaction and obtain the monohalogenated product.

The reported methodologies were applied only for the direct addition of chlorine, bromine and iodine to BCE and DBCE. The author pointed out the lack of relevant literature focused on the direct fluorination of aromatic crown ethers. ${ }^{43}$ In general, direct bromination of BCE is the most successful reaction among the protocols mentioned above, with yields that can exceed 90\%; chlorination and iodination are less performing due to either selectivity or stability reasons. Indeed, the most challenging aspect of the direct halogenation of DBCE is selectivity: the mono-substituted derivative is usually obtained in low yields since the reaction leads to the formation of mixtures of mono- and di-substituted species. Moreover, disubstituted derivatives could be obtained both as anti and syn isomers which can only be separated by fractional crystallisation. Higher yields (80-90\%) could be achieved in the preparation of the tetra-substituted derivatives.

Recently, Mobian et al. reported the bromination of DB24C8 (36) using sodium bromide (NaBr) and cerium(Iv) ammonium nitrate $\left[\left(\mathrm{NH}_{4}\right)_{2} \mathrm{Ce}\left(\mathrm{NO}_{3}\right)_{6}\right]$ in acetonitrile (Scheme 14)..$^{70}$ The reaction proceeds fast at room temperature and both mono- and di-functionalised adducts are formed. A yield of $39 \%$ was only reported for the mono-brominated derivative 37.

The addition of (halogen)methyl groups is briefly described in the review cited at the beginning of this section, ${ }^{43}$ where the approach reported by Biernat et al., ${ }^{71}$ involving the use of par-
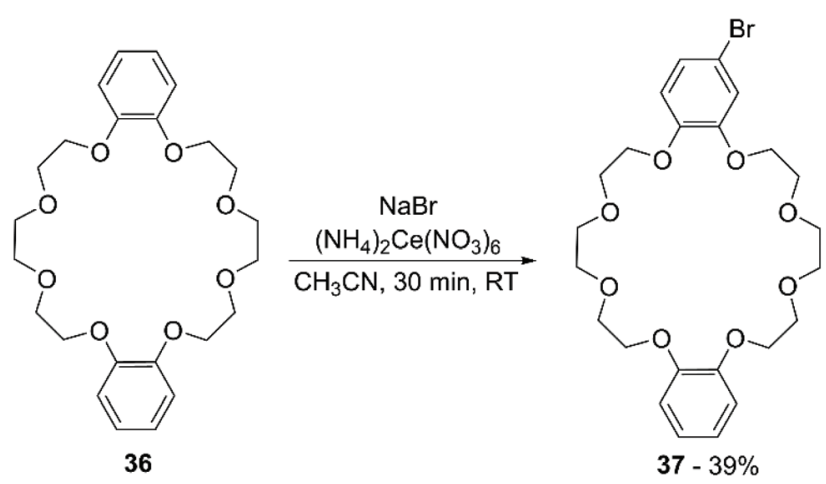

Scheme 14 Direct bromination of DB24C8 (36) with $\mathrm{NaBr}$.
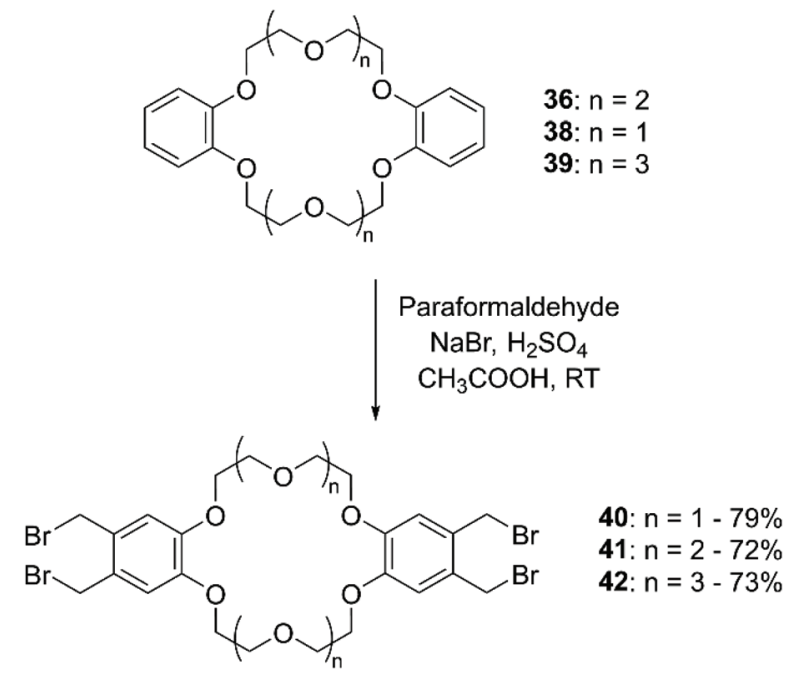

Scheme 15 Bromomethylation of DBCE.

aformaldehyde and hydrogen bromide in $\mathrm{CH}_{3} \mathrm{COOH}$, is given as an example for the bromomethylation of BCE and DBCE. An alternative procedure to obtain the tetra-bromomethylfunctionalised DBCE was reported by Nakamura et al., substituting $\mathrm{HBr}$ with a combination of sodium bromide $(\mathrm{NaBr})$ and $\mathrm{H}_{2} \mathrm{SO}_{4}$ (Scheme 15). ${ }^{72}$ Both methodologies led to yields that routinely exceeded $70 \%$.

Chloromethylation has been performed in a similar way, using formaldehyde and gaseous $\mathrm{HCl}$ (Scheme 16). Following this procedure, a 90\% yield of bis-chloromethylated B18C6 (43) was reported, ${ }^{73}$ while for DB18C6 a conversion of $70 \%$ was obtained, with the formation of $80 \%$ of the mono-chloromethylated derivative and $20 \%$ of the bis-chloromethylated product. $^{74}$

3.2.2. Functionalisation with nitro- and amino- groups. The routes to the direct functionalisation of aromatic crown ethers with nitro groups follow the many standardised protocols for the nitration of aromatic compounds. They typically involve the reaction of the substrate with nitric acid $\left(\mathrm{HNO}_{3}\right)$ in presence of either $\mathrm{CH}_{3} \mathrm{COOH}$ or $\mathrm{H}_{2} \mathrm{SO}_{4}$, to generate the electrophilic species, in $\mathrm{CHCl}_{3}$ at room temperature. The first example was reported by Feigenbaum et al. ${ }^{75}$ The procedure, which used a mixture of $\mathrm{HNO}_{3}$ and $\mathrm{CH}_{3} \mathrm{COOH}$ as nitrating solution, allowed to obtain the di-nitro derivative of 36 as both the syn (45) and anti (46) isomers, which were easily separated
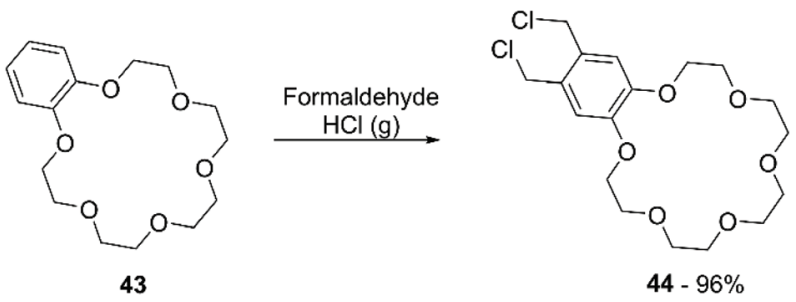

Scheme 16 Chloromethylation of B18C6 (43). 


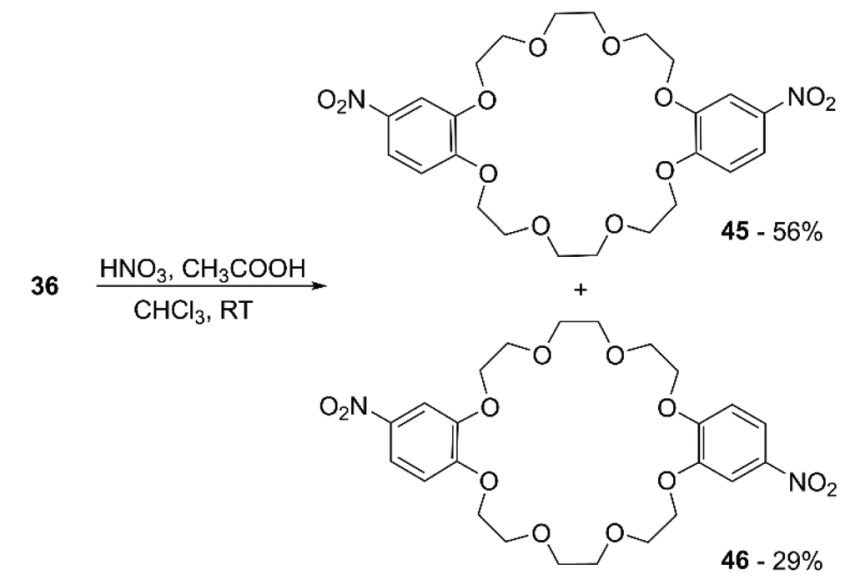

Scheme 17 Nitration of DB24C8 (36) according to the conditions reported by Feigenbaum et al.

by fractional crystallisation. The overall yield of the nitration reaction was $85 \%$, with an isolated yield of $34 \%$ for 46 (Scheme 17).

Slight variations of this protocol were adopted to convert B12C4, B15C5 and B18C6 into their mono-nitro ${ }^{76}$ and dinitro $^{77}$ derivatives in decent yields. Duggan et al. reported the synthesis of tetra-nitro derivatives of various DBCE in excellent yields, using $\mathrm{H}_{2} \mathrm{SO}_{4}$ instead of $\mathrm{CH}_{3} \mathrm{COOH}$ in the nitrating solution. ${ }^{78}$ Grebenyuk et al. described an alternative method for the nitration of $\mathrm{BCE}$ and $\mathrm{DBCE}$ with $\mathrm{KNO}_{3}$ and polyphosphoric acid (PPA). ${ }^{79}$ The process was carried out using a large excess of PPA, and different stoichiometric ratios between crown ether and $\mathrm{KNO}_{3}$ were tested; however, mixtures of mono- and di-nitro derivatives were obtained in all cases.

Nitro derivatives are important compounds since they can be easily and quantitatively reduced to amino compounds, which in turn can be converted to other functional groups either for further derivatisation with chromophores or to be introduced in polymers. ${ }^{75-77}$ It is worth noting, however, that amino functionalised CE undergo fast oxidation, particularly the di- and tetra-modified derivatives; thus, they must be handled under a controlled atmosphere and cannot be stored for a long time. ${ }^{77,78}$

A methodology for the direct amination of DB18C6 (38) was reported by Lyakhovnenko et al. using sodium azide $\left(\mathrm{NaN}_{3}\right)$ in PPA. ${ }^{80}$ Heating at $100{ }^{\circ} \mathrm{C}$ of an equimolar mixture of 38 and $\mathrm{NaN}_{3}$ in neat PPA led to the formation of the mono-functionalised derivative (47) in 61\% yield (Scheme 18).

3.2.3. Functionalisation with formyl- groups. Direct formylation of B15C5 was first achieved by Hyde et al. by means of the Vilsmeier reaction. ${ }^{81}$ Treating BCE with $\mathrm{N}$-methylformanilide in presence of $\mathrm{POCl}_{3}$ at $90{ }^{\circ} \mathrm{C}$ for $4 \mathrm{~h}$ yielded the mono-functionalised derivative in $30 \%$ yield. The demanding purification, which hampered the complete recovery of the product, pushed Wada et al. to resort to a different approach to functionalise B15C5 (48), B18C6 (43) and DB18C6 (38), adopting the classical Duff reaction for the formylation of
38

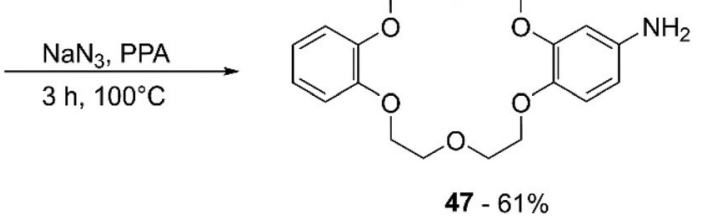

Scheme 18 Functionalisation of DB18C6 (38) with an amino group.

aromatics. $^{82}$ Accordingly, CE were mixed with hexamethylenetetramine (HMTA) in presence of trifluoroacetic acid (TFA) and stirred at $90{ }^{\circ} \mathrm{C}$ for 12 hours. In these conditions, one formyl group is introduced in BCE while DBCE undergo difunctionalisation, both in excellent yields (Scheme 19). It is interesting to note that, while the nitration of DBCE results in the formation of syn and anti isomers, formylation leads to the exclusive formation of the syn isomer.

Formylbenzocrowns represent useful intermediates, since they can be easily converted to a wide range of functional groups. CEs modified according to Wada's procedure have been used for the synthesis of molecular tweezers containing cyclidene-Ni complexes ${ }^{83}$ and BODIPY, ${ }^{84}$ and derivatised with benzimidazole, ${ }^{85}$ benzothiazolyl ${ }^{86}$ and porphyrins. ${ }^{87}$

3.2.4. Functionalisation with acyl- and alkyl- groups. Direct acylation of BCE and DBCE has been achieved either using carboxylic acids in presence of Eaton's reagent $\left(\mathrm{P}_{2} \mathrm{O}_{5}\right.$ and $\left.\mathrm{CH}_{3} \mathrm{SO}_{3} \mathrm{H}\right)$ or with carboxylic acids/anhydride and PPA. The first approach to be optimised is illustrated in Scheme $20 .^{88}$ BCE were mono-functionalised with a wide range of acyl moieties in good yields, while modified DBCE were obtained as mixture of syn and anti isomers that could be separated by recrystallisation or exploiting their different solubilities in organic solvents (Table 4).

The functionalisation using PPA for the generation of the electrophile is the most frequently adopted methodology and reported yields are comparable with the ones obtained using Eaton's reagent (Scheme 21). ${ }^{89}$ Saifullina et al. resorted to acetates as the source of acetyl group for the derivatisation of DBCE. It was demonstrated that there is a relation between the size of the counter cation of the acetate and the rate and regioselectivity of the reaction, due to the complexation between crown ether and cation. ${ }^{90}$ Acyl derivatives, analogously to formyl ones, are suitable precursors for several functional

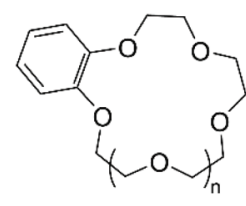

43: $n=2$

48: $n=1$

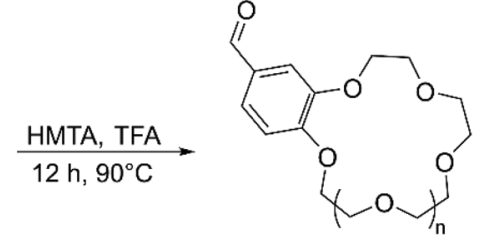

49: $\mathrm{n}=2-86 \%$

50: $n=1-82 \%$
Scheme 19 Functionalisation of BCE with formyl groups. 

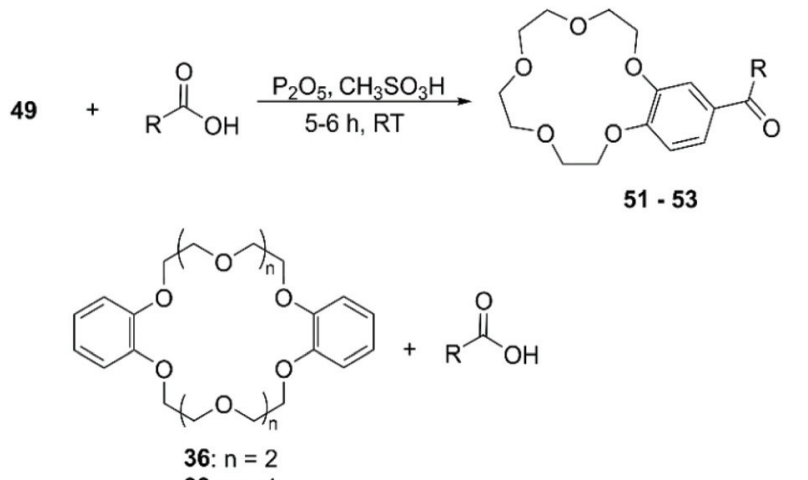

38: $n=1$

$$
\mid \begin{aligned}
& \mathrm{P}_{2} \mathrm{O}_{5}, \mathrm{CH}_{3} \mathrm{SO}_{3} \mathrm{H} \\
& 5-6 \mathrm{~h}, \mathrm{RT}
\end{aligned}
$$

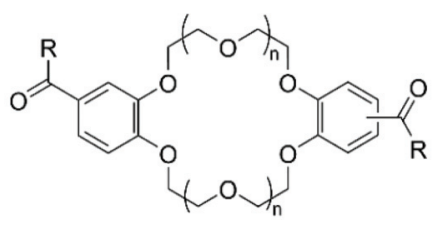

$54-64: n=1$

$65-68: n=2$

Scheme 20 Acylation of BCE and DBCE using Eaton's reagent.

Table 4 Products of the acylation using Eaton's reagent and yields ${ }^{88}$

\begin{tabular}{llllll}
\hline Prod. & $R$ & Yield (\%) & Prod. & $R$ & Yield (\%) \\
\hline $\mathbf{5 1}$ & $\mathrm{CH}_{3}$ & 63 & $\mathbf{6 0}$ & $\mathrm{CH}_{3}\left(\mathrm{CH}_{2}\right)_{7}$ & 84 \\
$\mathbf{5 2}$ & $\mathrm{CH}_{3}\left(\mathrm{CH}_{2}\right)_{5}$ & 55 & $\mathbf{6 1}$ & $\mathrm{CH}_{3}\left(\mathrm{CH}_{2}\right)_{8}$ & 75 \\
$\mathbf{5 3}$ & $\mathrm{CH}_{3}\left(\mathrm{CH}_{2}\right)_{12}$ & 26 & $\mathbf{6 2}$ & $\mathrm{CH}_{3}\left(\mathrm{CH}_{2}\right)_{10}$ & 79 \\
$\mathbf{5 4}$ & $\mathrm{CH}_{3}$ & 86 & $\mathbf{6 3}$ & $\mathrm{CH}\left(\mathrm{CH}_{3}\right)_{2}$ & 88 \\
$\mathbf{5 5}$ & $\mathrm{CH}_{3} \mathrm{CH}_{2}$ & 66 & $\mathbf{6 4}$ & $\mathrm{C}\left(\mathrm{CH}_{3}\right)_{3}$ & 85 \\
$\mathbf{5 6}$ & $\mathrm{CH}_{3}\left(\mathrm{CH}_{2}\right)_{2}$ & 72 & $\mathbf{6 5}$ & $\mathrm{CH}_{3}\left(\mathrm{CH}_{2}\right)_{3}$ & 66 \\
$\mathbf{5 7}$ & $\mathrm{CH}_{3}\left(\mathrm{CH}_{2}\right)_{3}$ & 100 & $\mathbf{6 6}$ & $\mathrm{CH}_{3}\left(\mathrm{CH}_{2}\right)_{8}$ & 84 \\
$\mathbf{5 8}$ & $\mathrm{CH}_{3}\left(\mathrm{CH}_{2}\right)_{4}$ & 78 & $\mathbf{6 7}$ & $\mathrm{CH}_{3}\left(\mathrm{CH}_{2}\right)_{10}$ & 53 \\
$\mathbf{5 9}$ & $\mathrm{CH}_{3}\left(\mathrm{CH}_{2}\right)_{5}$ & 86 & $\mathbf{6 8}$ & $\mathrm{CH}_{3}\left(\mathrm{CH}_{2}\right)_{12}$ & 85
\end{tabular}

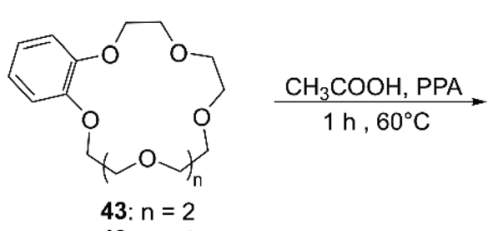

48: $n=1$

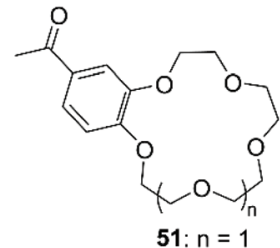

69: $n=2$
Scheme 21 Conditions for the acetylation of aromatic crown ethers.

groups including vinyl, ${ }^{91}$ ester $^{92}$ and $\alpha, \beta$-unsaturated ketones. ${ }^{93}$ Although acylated $\mathrm{CE}$ can be reduced in order to obtain alkyl derivatives, different procedures have been devised for the direct alkylation of BCE and DBCE. Alcohols in combination with $\mathrm{PPA}^{94}$ or sulfuric acid $\left(\mathrm{H}_{2} \mathrm{SO}_{4}\right)^{95}$ have been used for the introduction of alkyl groups on aromatic CE. The outcome of the reaction proved to be dependent on the nature of the alcohol used and the size of the CE. Moreover, in addition to the formation of regioisomers, these routes exhibited a poor control on the number of functional groups added to the CE substrate.

3.2.5. Functionalisation with sulfonate and sulfonyl chloride groups. Sasaki et al. described the sulfonation of BCE and DBCE using $\mathrm{H}_{2} \mathrm{SO}_{4}$ in acetonitrile. ${ }^{96}$ While for both mono-sulfonation of BCE and di-sulfonation of DBCE high yields were reported $(90 \%)$, more recent literature reports confirmed that di-sulfonated species are usually obtained as mixtures of isomers, whose properties could significantly vary from one another. ${ }^{97}$ Sulfonated CE have been isolated as tetrabutylammonium salts, which are endowed with a better solubility in water and other protic solvents (Scheme 22).

An alternative approach to sulfonation is based on the use of potassium sulfate in PPA. ${ }^{98}$ This methodology afforded sulfonated BCE and DBCE in good yields. Sulfonated CE can be readily converted by treatment with sulfonyl chloride to their chlorosulfonate derivative, which in turn can be reduced to produce thiol-functionalised BCE. ${ }^{99}$ A reported case of a good yielding direct chloro-sulfonation of aromatic CE involves the use of chlorosulfonic acid in chloroform. ${ }^{100}$

3.2.6. Functionalisation with other groups. BCE have been functionalised with diphenylglycouril fragments to create molecular tweezers and clips characterised by a rigid backbone connecting two crown ether units. The original procedure by Nolte et al. envisaged the reaction of B15C5 with the tetrachloride derivative of diphenylglycouril in the presence of tin chloride $\left(\mathrm{SnCl}_{4}\right)$ to obtain the bis-functionalised derivative in $92 \%$ yield. ${ }^{101}$ Later, Bogaschenko et al. tried to reproduce the result, but reported lower yields which were in part ascribed to a challenging purification of the product. Hence, they tested a range of reaction conditions and diphenylglycouril derivatives in order to find an optimal procedure for the synthesis of molecular clips. ${ }^{102}$ The final proposed protocol relies on the use of bis(cyclomethoxymethylene)diphenylglycoluril as a precursor in the presence of PPA. Higher yields $(>70 \%)$ were reported for smaller CE (80-82), while macrocycles character-
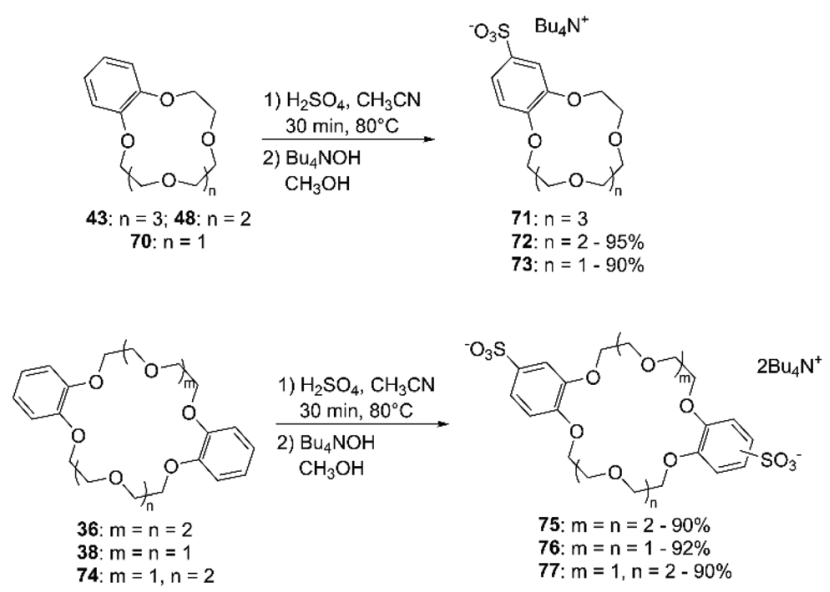

Scheme 22 Direct sulfonation of BCE and DBCE. 


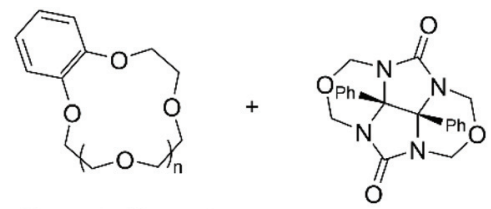

43: $\mathrm{n}=3 ; 48: \mathrm{n}=2$;

$70: n=1 ; 78: n=4$

79: $n=5$

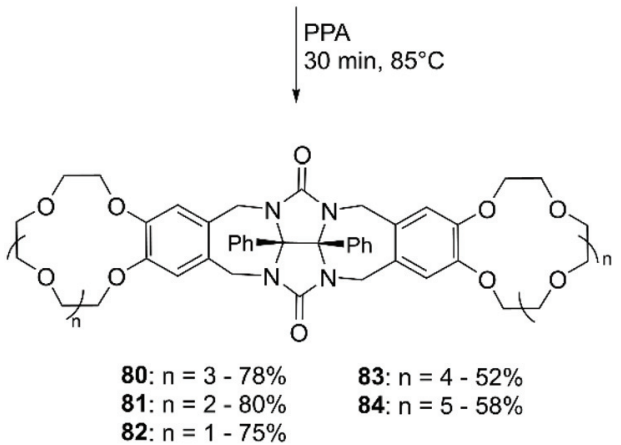

Scheme 23 Functionalisation of BCE with diphenylglycouril for the preparation of molecular clips.

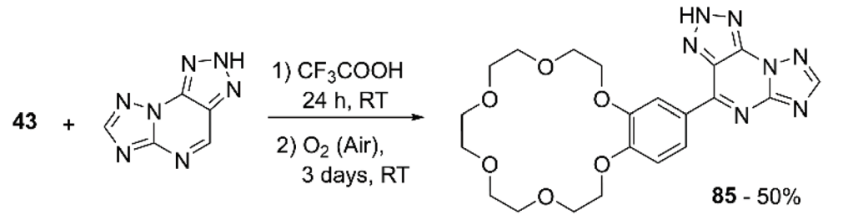

Scheme 24 Functionalisation of B18C6 (43) with 8-azapurine analogues.

ised by wider cavities $(\mathbf{8 3}, \mathbf{8 4})$ were isolated in $50 \%$ yields (Scheme 23).

Gorbunov et al. developed a synthetic methodology for the introduction of aromatic ethers and thiophene onto $\mathrm{H}$-azolo $[1,5-a][1-3]$ triazolo[4,5-e]pyrimidines, analogues of 8 -azapurines, aiming to develop compounds that present enhanced biological activity by the combination of multiple pharmacophore fragments. ${ }^{103}$ The process involves a nucleophilic displacement of hydrogen $\left(\mathrm{S}_{\mathrm{N}}{ }^{\mathrm{H}}\right)$ reaction characterised by a two-step addition-oxidation mechanism. B18C6 was considered for the scope of the reaction. Mixing the $\mathrm{CE}$ with the pyrimidine derivative in trifluoroacetic acid $\left(\mathrm{CF}_{3} \mathrm{COOH}\right)$ allows the formation of the addition product, which is then oxidised to 85 in $50 \%$ yield by exposure to atmospheric oxygen over a threeday period (Scheme 24).

\section{Conclusions}

Crown ethers (CE) are a most prominent class of macrocyclic compounds in supramolecular science and technology. Their versatility as host molecules for cationic and neutral species allowed for their application in a wide range of fields including catalysis, separation and purification, transport and delivery of ionic species, mechanically interlocked molecules and materials, and molecular machines. The growing complexity of systems of this kind and the interest in enriching the behaviour of $\mathrm{CE}$ as host compounds with other functions, has led to a growing need for the development of methodologies for the synthesis of derivatised macrocyclic polyethers that could be easily inserted into elaborated architectures.

Functionalised $\mathrm{CE}$ can be obtained either by templated macrocyclisation, using appropriately substituted starting materials, or through synthetic routes for the direct introduction of moieties on pre-formed macrocycles. Direct functionalisation of aliphatic CE is generally performed using cross dehydrogenative coupling (CDC) reactions: the process follows a radical mechanism initiated photochemically or thermally. Mono-functionalised aliphatic CE are thus obtained in good yields, albeit a large excess of the starting substrate is required. A wide range of functional groups has been introduced on BCE and DBCE via electrophilic aromatic substitution. Control over the number of moieties added on the product and regioselectivity represent the principal challenges in this case.

Despite the significant potential in the context of contemporary chemistry, the procedures dealing with the direct functionalisation of $\mathrm{CE}$ are quite scattered in the literature, and some of them are mere adaptations of general protocols. A focused optimisation of reaction conditions to fit the properties and structural characteristics of CE would allow a full exploitation of the opportunities offered by this approach, particularly with regard to the post-synthetic modification of sophisticated CE-based architectures. Indeed, the direct functionalisation of crown ethers could provide a valuable alternative to templated macrocyclisation, by reducing the synthetic effort and opening new routes to exploit this ceaselessly fascinating class of macrocycles.

\section{Author Contributions}

F. Nicoli: conceptualization, analysis, writing-original draft; M. Baroncini: supervision, writing-review and editing; S. Silvi: writing-review and editing; J. Groppi: conceptualization, analysis, writing-original draft; A. Credi: supervision, funding acquisition, writing-review and editing.

\section{Conflicts of interest}

The authors declare no conflict of interest.

\section{Acknowledgements}

Financial support from the European Union's H2020 Research and Innovation Program (FET-OPEN "MAGNIFY" No. 801378 and ERC AdG "LEAPs” No. 692981) is gratefully acknowledged. 


\section{Notes and references}

1 (a) L. H. Cretcher and W. H. Pittenger, Syntheses with $\beta$, $\beta$ '-dichloro-diethyl ether, J. Am. Chem. Soc., 1925, 47, 163166; (b) G. F. Zellhoefer, Solubility of halogenated hydrocarbon refrigerants in organic solvents, Ind. Eng. Chem., 1937, 29, 548-551; (c) J. L. Down, J. Lewis, B. Moore and G. Wilkinson, The solubility of alkali metals in ethers, J. Chem. Soc., 1959, 3767-3773.

2 (a) C. J. Pedersen, Cyclic polyethers and their complexes with metal salts, J. Am. Chem. Soc., 1967, 89, 7017-7036; (b) C. J. Pedersen, New macrocyclic polyethers, J. Am. Chem. Soc., 1970, 92, 391-394.

3 C. J. Pedersen, The discovery of crown ethers (Nobel lecture), Angew. Chem., Int. Ed. Engl., 1988, 27, 1021-1027.

4 J.-M. Lehn, Supramolecular chemistry-scope and perspectives molecules, supermolecules, and molecular devices (Nobel Lecture), Angew. Chem., Int. Ed. Engl., 1988, 27, 89-112.

5 D. J. Cram, The design of molecular hosts, guests, and their complexes (Nobel lecture), Angew. Chem., Int. Ed. Engl., 1988, 27, 1009-1020.

6 (a) J.-M. Lehn, Supramolecular Chemistry - Concepts and Perspectives, WileyVCH, Weinheim, 1995; (b) J. W. Steed and J. L. Atwood, Supramolecular Chemistry, Wiley, Chichester, 2nd edn, 2009.

7 (a) G. W. Gokel, Crown Ethers and Cryptands, RSC Publishing, Cambridge, 1991; (b) G. W. Gokel, S. Negin and R. Cantwell, in Comprehensive Supramolecular Chemistry II, eds. J. L. Atwood, G. W. Gokel and L. J. Barbour, Elsevier, Amsterdam, 2017, vol. 3, pp. 3-48.

8 (a) G. W. Gokel, W. M. leevy and M. E. Weber, Crown ethers: sensors for ions and molecular scaffolds for materials and biological models, Chem. Rev., 2004, 104, 2723-2750; (b) B. Zheng, F. Wang, S. Dong and F. Huang, Supramolecular polymers constructed by crown etherbased molecular recognition, Chem. Soc. Rev., 2012, 41, 1621-1636; (c) S. Shirakawa and K. Maruoka, Recent developments in asymmetric phase-transfer reactions, Angew. Chem., Int. Ed., 2013, 52, 4312-4348; (d) I. V. Kolesnichenko and E. V. Anslyn, Practical applications of supramolecular chemistry, Chem. Soc. Rev., 2017, 46, 2385-2390; (e) J. Li, D. Yim, W.-D. Jang and J. Yoon, Recent progress in the design and applications of fluorescence probes containing crown ethers, Chem. Soc. Rev., 2017, 46, 2437-2458; (f) H.-W. Schmidt and F. Würthner, A periodic system of supramolecular elements, Angew. Chem., Int. Ed., 2020, 59, 8766-8775.

9 (a) P. R. Ashton, E. J. T. Chrystal, J. P. Mathias, K. P. Parry, A. M. Z. Slawin, N. Spencer, J. F. Stoddart and D. J. Williams, Complexation of diquat and paraquat by macrocyclic polyethers incorporating two dibydroxynaphthalene residues, Tetrahedron Lett., 1987, 28, 63676370; (b) O. Š. Miljanić and J. F. Stoddart, Dynamic donor-acceptor [2]catenanes, Proc. Natl. Acad. Sci. U. S. A., 2007, 104, 12966-12970; (c) A. Gumus, S. Karadeniz,
H. I. Ugras, M. Bulut, U. Cakir and A. C. Goren, Synthesis, complexation, and biological activity studies of 4-aminomethyl-7,8-dihydroxy coumarines and their crown ether derivatives, J. Heterocycl. Chem., 2010, 47, 11271133; (d) G. Barin, A. Coskun, D. C. Friedman, M. A. Olson, M. T. Colvin, R. Carmielli, S. K. Dey, O. A. Bozdemir, M. R. Wasielewski and J. F. Stoddart, A multistate switchable [3]rotacatenane, Chem. - Eur. J., 2011, 17, 213-222; (e) H. Maeda, K. Nakamura, T. Furuyama and M. Segi, (1,3)pyrenophanes containing crown ether moieties as fluorescence sensors for metal and ammonium ions, Photochem. Photobiol. Sci., 2019, 18, 2397-2410; $(f)$ M. Gaedke, F. Witte, J. Anhauser, H. Hupatz, H. V. Schroder, A. Valkonen, K. Rissanen, A. Lutzen, B. Paulus and C. A. Schalley, Chiroptical inversion of a planar chiral redox-switchable rotaxane, Chem. Sci., 2019, 10, 10003-10009.

10 G. W. Gokel and H. D. Durst, Principles and synthetic applications in crown ether chemistry, Synthesis, 1976, 168-184.

11 (a) P. L. Anelli, B. Czech, F. Montanari and S. Quici, Reaction mechanism and factors influencing phase-transfer catalytic activity of crown ethers bonded to a polystyrene matrix, J. Am. Chem. Soc., 1984, 106, 861-869; (b) G. Pozzi, S. Quici and R. H. Fish, Fluorous phase transfer catalysts: From onium salts to crown ether, J. Fluor. Chem., 2008, 129, 920-929; (c) R. Schettini, M. Sicignano, F. De Riccardis, I. Izzo and G. Della Sala, Macrocyclic hosts in asymmetric phase-transfer catalyzed reactions, Synthesis, 2018, 4777-4795.

12 (a) A. H. Bond, M. L. Dietz and R. Chiarizia, Incorporating size selectivity into synergistic solvent extraction: a review of crown ether-containing systems, Ind. Eng. Chem. Res., 2000, 39, 3442-3464; (b) F. W. van Leeuwen, W. Verboom and D. N. Reinhoudt, Selective extraction of naturally occurring radioactive $\mathrm{Ra}^{2+}$, Chem. Soc. Rev., 2005, 34, 753761; (c) J. Wang and S. Zhuang, Cesium separation from radioactive waste by extraction and adsorption based on crown ethers and calixarenes, Nucl. Eng. Technol., 2020, 52, 328-336.

13 (a) G. W. Gokel and M. M. Dashbach, Coordination and transport of alkali metal cations through phospholipid bilayer membranes by hydraphile channels, Coord. Chem. Rev., 2008, 252, 886-902; (b) N. Sakai and S. Matile, Synthetic ion channels, Langmuir, 2013, 29, 9031-9040; (c) S.-P. Zheng, L.-B. Huang, Z. Sun and M. Barboiu, Selfassembled artificial ion-channels toward natural selection of functions, Angew. Chem., Int. Ed., 2021, 60, 566-597.

14 (a) J. Krane and T. Skjetne, Studies of crown ether complexes aryldiazonium ion complexes, Tetrahedron Lett., 1980, 21, 1775-1778; (b) J. R. Beadle, D. M. Dishong, R. K. Khanna and G. W. Gokel, Syntheses and properties of arenediazonium and anilinium cation lariat ether complexes: an "ostrich molecule" complex and evidence for intramolecular sidearm-macroring interaction, Tetrahedron, 1984, 40, 3935-3944; (c) H. Nakazumi, 
T. Kitao and H. Zollinger, Dediazoniation of arenediazonium ions. 24. Dual and triple substituent parameter evaluation of competitive heterolytic and homolytic dediazoniations of diazonium ions complexed with 18-crown-6 ether, J. Org. Chem., 1987, 52, 2825-2830.

15 (a) L. Pospisil and R. Fuoco, Complex formation of methyl viologen and diquat with macrocyclic ether dibenzo-24crown-8, J. Electroanal. Chem., 1988, 240, 105-116; (b) A. B. Braunschweig, C. M. Ronconi, J.-Y. Han, F. Aricò, S. J. Cantrill, J. F. Stoddart, S. I. Khan, A. J. P. White and D. J. Williams, Pseudorotaxanes and rotaxanes formed by viologen derivatives, Eur. J. Org. Chem., 2006, 1857-1866.

16 P. R. Ashton, S. E. Boyd, A. Brindel, S. J. Langford, S. Menzer, L. Perez-Garcia, J. A. Preece, F. M. Raymo, N. Spencer, J. F. Stoddart, A. J. P. White and D. J. Williams, Diazapyrenium-containing catenanes and rotaxanes, New J. Chem., 1999, 23, 587-602.

17 S. J. Loeb and J. A. Wisner, A new motif for the selfassembly of [2]pseudorotaxanes; 1,2-bis(pyridinium) ethane axles and 24-crown-8 ether wheels, Angew. Chem., Int. Ed., 1998, 37, 2838-2840.

18 (a) S. Kiviniemi, M. Nissen, M. T. Lamsa, J. Jalonen, K. Rissanen and J. Pursiainen, Complexation of planar, organic, five-membered cations with crown ethers, New J. Chem., 2000, 24, 47-52; (b) N. Noujeim, K. Zhu, N. Vukotich and S. J. Loeb, [2]pseudorotaxanes from T-shaped benzimidazolium axles and 24-crown-8 wheels, Org. Lett., 2012, 14, 2484-2487.

19 G. Ragazzon, A. Credi and B. Colasson, Thermodynamic insights on a bistable acid-base switchable molecular shuttle with strongly shifted co-conformational equilibria, Chem. - Eur. J., 2017, 23, 2149-2156.

20 R. M. Izatt, J. D. Lamb, N. E. Izatt, B. E. Rossiter, Jr., J. J. Christensen and B. L. Haymore, A calorimetric titration study of the reaction of several organic ammonium cations with 18-crown-6 in methanol, J. Am. Chem. Soc., 1979, 101, 6273-6276.

21 P. R. Ashton, E. J. T. Chrystal, P. T. Glink, S. Menzer, C. Schiavo, N. Spencer, J. F. Stoddart, P. A. Tasker, A. J. P. White and D. J. Williams, Pseudorotaxanes formed between secondary dialkylammonium salts and crown ethers, Chem. - Eur. J., 1996, 2, 709-728.

22 J. Groppi, L. Casimiro, M. Canton, S. Corra, M. JafariNasab, G. Tabacchi, L. Cavallo, M. Baroncini, E. Fois and A. Credi, Precision molecular threading/dethreading, Angew. Chem., Int. Ed., 2020, 59, 14825-14834.

23 See, e.g.: E. Ishow, A. Credi, V. Balzani, F. Spadola and L. Mandolini, A molecular-level plug/socket system: electronic energy transfer from a binaphthyl unit incorporated into a crown ether to an anthracenyl unit linked to an ammonium ion, Chem. - Eur. J., 1999, 5, 984-989.

24 C. J. Bruns and J. F. Stoddart, The Nature of the Mechanical Bond: From Molecules to Machines, Wiley, Hoboken, 2016.

25 V. Balzani, A. Credi and M. Venturi, Molecular Devices and Machines - Concepts and Perspectives for the Nanoworld, Wiley-VCH, Weinheim, 2008.
26 (a) S. Erbas-Cakmak, D. A. Leigh, C. T. McTernan and A. L. Nussbaumer, Artificial molecular machines, Chem. Rev., 2015, 115, 10081-10206; (b) M. Baroncini, S. Silvi and A. Credi, Photo-and redox-driven artificial molecular motors, Chem. Rev., 2020, 120, 200-268.

27 Recent representative examples: (a) G. Ragazzon, C. Schäfer, P. Franchi, S. Silvi, B. Colasson, M. Lucarini and A. Credi, Remote electrochemical modulation of $\mathrm{pKa}$ in a rotaxane by co-conformational allostery, Proc. Natl. Acad. Sci. U. S. A., 2018, 115, 9385-9390; (b) Q. Zhang, S.-J. Rao, X. Tao, X. Li, T.-Y. Xu, D.-W. Li, D.-H. Qu, Y.-T. Long and H. Tian, Muscle-like artificial molecular actuators for nanoparticles, Chem, 2018, 4, 2670-2684; (c) B. Riss-Yaw, C. Clavel, P. Laurent, P. Waeles and F. Coutrot, The importance of length and flexibility of macrocycle-containing molecular translocators for the synthesis of improbable [2]rotaxanes, Chem. - Eur. J., 2018, 24, 13659-13666; (d) J.-J. Yu, L.-Y. Zhao, Z.-T. Shi, Q. Zhang, G. London, W.-J. Liang, C. Gao, M.-M. Li, X.-M. Cao, H. Tian, B. L. Feringa and D.-H. Qu, Pumping a ring-sliding molecular motion by a light-powered molecular motor, J. Org. Chem., 2019, 84, 5790-5802; (e) H. W. Schroeder, F. Stein, J. M. Wollschlager, S. Sobottka, M. Gaedke, B. Sarkar and C. A. Schalley, Accordion-like motion in electrochemically switchable crown ether/ammonium oligorotaxanes, Angew. Chem., Int. Ed., 2019, 58, 3496-3500; $(f)$ G. Baggi, L. Casimiro, M. Baroncini, S. Silvi, A. Credi and S. J. Loeb, Threadinggated photochromism in [2]pseudorotaxanes, Chem. Sci., 2019, 10, 5104-5113; (g) Y. Sagara, M. Karman, A. Seki, M. Pannipara, N. Tamaoki and C. Weder, Rotaxane-based mechanophores enable polymers with mechanically switchable white photoluminescence, ACS Cent. Sci., 2019, 5, 874-881.

28 (a) G. Ragazzon, M. Baroncini, S. Silvi, M. Venturi and A. Credi, Light-powered autonomous and directional molecular motion of a dissipative self-assembling system, Nat. Nanotechnol., 2015, 10, 70-75; (b) S. Erbas-Cakmak, S. D. P. Fielden, U. Karaca, D. A. Leigh, C. T. McTernan, D. J. Tetlow and M. R. Wilson, Rotary and linear molecular motors driven by pulses of a chemical fuel, Science, 2017, 358, 340-343.

29 (a) C. Yoo, H. M. Dodge and A. J. M. Miller, Cation-controlled catalysis with crown ether-containing transition metal complexes, Chem. Commun., 2019, 55, 5047-5059; (b) S. Di Stefano, G. Capocasa and L. Mandolini, Supramolecular catalysts featuring crown ethers as recognition units, Eur. J. Org. Chem., 2020, 3340-3350; (c) M. Zuo, K. Velmurugan, K. Wang, X. Tian and K.-Y. Hu, Insight into functionalized-macrocycles-guided supramolecular photocatalysis, Beilstein J. Org. Chem., 2021, 17, 139-155.

30 (a) K. Ghosh, H.-B. Yang, B. H. Northrop, M. M. Lyndon, Y.-R. Zheng, D. C. Muddiman and P. J. Stang, Coordination-driven self-assembly of cavity-cored multiple crown ether derivatives and poly [2]pseudorotaxanes, 
J. Am. Chem. Soc., 2008, 130, 5320-5334; (b) S. Schneider, E.-D. Licsandru, I. Kocksis, A. Gilles, F. Dumitru, E. Moulin, J. Tan, J.-M. Lehn, N. Giuseppone and M. Barboiu, Columnar self-assemblies of triarylamines as scaffolds for artificial biomimetic channels for ion and for water transport, J. Am. Chem. Soc., 2017, 139, 37213727; (c) S. Dong, L. Wang, J. Wu, L. Jin, Y. Ge, Z. Qi and C. Wu, Thermosensitive phase behavior of benzo-21crown-7 and its derivatives, Langmuir, 2017, 33, 1386113866; (d) S. Dong, J. Leng, Y. Feng, M. Liu, C. J. Stackhouse, A. Schönhals, L. Chiappisi, L. Gao, W. Chen, J. Shang, L. Jin, Z. Qi and C. A. Schalley, Structural water as an essential comonomer in supramolecular polymerization, Sci. Adv., 2017, 3, 1-8; (e) A. Abdelfatah, M. Mohammed and H.-C. Lin, The crown ether size and stereochemistry affect the self-assembly, hydrogelation, and cellular interactions of crown ether/peptide conjugates, J. Mater. Chem. B, 2020, 8, 99619970.

31 (a) A. V. Tsukanov, A. D. Dubonosov, V. A. Bren and V. I. Minkin, Organic chemosensors with crown-ether groups, Chem. Heterocycl. Compd., 2008, 44, 899-923; (b) I. Moczar and P. Huszthy, Optically active crown etherbased fluorescent sensor molecules: A mini-review, Chirality, 2019, 31, 97-109; (c) R. M. Kakhki and M. Rakhshanipour, Application of nanoparticle modified with crown ether in colorimetric determinations, Arabian J. Chem., 2019, 12, 3096-3107; (d) K. Sambath, X. Liu, Z. Wan, L. Hutnik, K. D. Belfield and Y. Zhang, Potassium ion fluorescence probes: structures, properties and bioimaging, ChemPhotoChem, 2021, 5, 317-325.

32 (a) V. Percec, G. Johansson, G. Ungar and J. Zhou, Fluorophobic effect induces the self-assembly of semifluorinated tapered monodendrons containing crown ethers into supramolecular columnar dendrimers which exhibit a homeotropic hexagonal columnar liquid crystalline phase, J. Am. Chem. Soc., 1996, 118, 9855-9866; (b) H. W. Gibson, N. Yagamuci, L. Hamilton and J. W. Jones, Cooperative self-assembly of dendrimers via pseudorotaxane formation from a homotritopic guest molecule and complementary monotopic host dendrons, J. Am. Chem. Soc., 2002, 124, 4653-4665; (c) G. M. Dykes and D. K. Smith, Supramolecular dendrimer chemistry: using dendritic crown ethers to reversibly generate functional assemblies, Tetrahedron, 2003, 59, 3999-4009; (d) M. Tanaka, Y. Higuci, N. Adachi, Y. Shibutani, S. A. Ahmed, S. Kado, M. Nakamura and K. Kimura, Crowned dendron: Ion-responsive flexibility of macromolecules induced by integrated crown ether moieties, Tetrahedron, 2005, 61, 8159-8166; (e) D. Alivertis, V. Theodorou, G. Paraskevopoulos and K. Skobridis, Searching for new host compounds: synthesis and characterization of novel crown ether-functionalized dendrimers, Tetrahedron Lett., 2007, 48, 4091-4095.

33 (a) J. Smid, Ion-binding properties of crown ether and cryptand containing polymers, Ind. Eng. Chem. Prod. Res.
Dev., 1980, 19, 364-371; (b) U. Tunca and Y. Yagci, Crown ether-containing polymers, Prog. Polym. Sci., 1994, 19, 233-286; (c) S. D. Alexandratos and C. L. Stine, Synthesis of ion-selective polymer-supported crown ethers: a review, React. Funct. Polym., 2004, 60, 3-16; (d) D. Xia, P. Wang, X. Ji, N. M. Khashab, J. L. Sessler and F. Huang, Functional supramolecular polymeric networks: the marriage of covalent polymers and macrocycle-based hostguest interactions, Chem. Rev., 2020, 120, 6070-6123.

34 (a) C. Yuan, S. Fu, K. Yang, B. Hou, Y. Liu, J. Jiang and Y. Cui, Crystalline $\mathrm{C}-\mathrm{C}$ and $\mathrm{C}=\mathrm{C}$ bond-linked chiral covalent organic frameworks, J. Am. Chem. Soc., 2021, 143, 369-381; (b) S. An, Q. Xu, Z. Ni, J. Hu, C. Peng, L. Zhai, Y. Guo and H. Liu, Construction of covalent organic frameworks with crown ether struts, Angew. Chem., Int. Ed., 2021, 60, 9959-9963.

35 W. Gong, W. Zhang, F. A. Son, K. Yang, Z. Chen, X. Chen, J. Jiang, Y. Liu, O. K. Farha and Y. Cui, Topological straininduced regioselective linker elimination in a chiral $\mathrm{Zr}(\mathrm{IV})-$ based metal-organic framework, Chem, 2021, 7, 190-201.

36 (a) M. Zhang, D. Xu, X. Yan, J. Chen, S. Dong, B. Zheng and F. Huang, Self-healing supramolecular gels formed by crown ether based host-guest interactions, Angew. Chem., Int. Ed., 2012, 51, 7011-7015; (b) F. Ishiwari, K. Nakazono, Y. Koyama and T. Takata, Induction of single-handed helicity of polyacetylenes using mechanically chiral rotaxanes as chiral Sources, Angew. Chem., Int. Ed., 2017, 56, 14858-15862; (c) L. Wang, L. Cheng, G. Li, K. Liu, Z. Zhang, P. Li, S. Dong, W. Yu, F. Huang and $\mathrm{X}$. Yan, A self-cross-linking supramolecular polymer network enabled by crown-ether-based molecular recognition, J. Am. Chem. Soc., 2020, 142, 2051-2058; (d) T. Takata, Switchable polymer materials controlled by rotaxane macromolecular switches, ACS Cent. Sci., 2020, 6, 129-143.

37 (a) X. Yan, B. Zheng and F. Huang, Integrated motion of molecular machines in supramolecular polymeric scaffolds, Polym. Chem., 2013, 4, 2395-2399; (b) H.-Y. Zhou, Q.-S. Zong, Y. Han and C.-F. Chen, Recent advances in higher order rotaxane architectures, Chem. Commun., 2020, 56, 9916-9936; (c) N. H. Perez and J. E. M. Lewis, Synthetic strategies towards mechanically interlocked oligomers and polymers, Org. Biomol. Chem., 2020, 18, 6757-6780; (d) C.-S. Kwan and K. C.-F. Leung, Development and advancement of rotaxane dendrimers as switchable macromolecular machines, Mater. Chem. Front., 2020, 4, 2825-2844.

38 C. Schäfer, G. Ragazzon, B. Colasson, M. La Rosa, S. Silvi and A. Credi, An artificial molecular transporter, ChemistryOpen, 2016, 5, 120-124.

39 (a) E. M. G. Jamieson, F. Modicom and S. M. Goldup, Chirality in rotaxanes and catenanes, Chem. Soc. Rev., 2018, 47, 5266-5311; (b) S. Corra, C. de Vet, J. Groppi, M. La Rosa, S. Silvi, M. Baroncini and A. Credi, Chemical on/off switching of mechanically planar chirality and chiral anion recognition in a [2] rotaxane molecular 
shuttle, J. Am. Chem. Soc., 2019, 141, 9129-9133; (c) C. Tian, S. D. P. Fielden, B. Perez-Saavedra, I. J. Vitorica-Yrezabal and D. A. Leigh, Single-step enantioselective synthesis of mechanically planar chiral [2] rotaxanes using a chiral leaving group strategy, J. Am. Chem. Soc., 2020, 142, 9803-9808; (d) A. Imayoshi, B. V. Lakshimi, Y. Ueda, T. Yoshimura, A. Matayoshi, T. Furuta and T. Kawabata, Enantioselective preparation of mechanically planar chiral rotaxanes by kinetic resolution strategy, Nat. Commun., 2021, 12(404)), 1-7.

40 (a) W. Li, W. Zhang, O. Š. Miljanić, C.-H. Sue, Y.-L. Zhao, L. Liu, C. B. Knobler, J. F. Stoddart and O. M. Yaghi, Docking in metal-organic frameworks, Science, 2009, 325, 855-859; (b) K. Zhu, C. A. O'Keefe, V. N. Vukotic, R. W. Shurko and S. J. Loeb, A molecular shuttle that operates inside a metal-organic framework, Nat. Chem., 2015, 7, 514-519; (c) B. H. Wilson and S. J. Loeb, Integrating the mechanical bond into metal-organic frameworks, Chem, 2020, 6, 1604-1612.

41 J. S. Bradshaw and P. E. Stott, Preparation of derivatives and analogs of the macrocyclic oligomers of ethylene oxide (Crown compounds), Tetrahedron, 1980, 36, 461-510.

42 A. Homberg and J. Lacour, From reactive carbenes to chiral polyether macrocycles in two steps-synthesis and applications made easy?, Chem. Sci., 2020, 11, 6362-6369.

43 S. M. Pluzhnik-Gladyr, Halogen derivatives of benzo-and dibenzocrown ethers: synthesis, structure, properties and application, Russ. Chem. Rev., 2016, 86, 172-203.

44 (a) B. R. Bowsher and A. J. Rest, Template synthesis and ionophorous properties of substituted crown ethers towards alkali-metal ions, J. Chem. Soc. Dalton Trans., 1984, 1421-1425; (b) B. Czech, Alternative, simple route to hydroxymethyl crown ethers, Tetrahedron Lett., 1980, 21, 4197-4198; (c) H. Maeda, T. Kikui, Y. Nakatsuji and M. Okahara, Synthesis of aminomethyl crown ethers, J. Org. Chem., 1982, 47, 5167-5171.

45 (a) I. Ikeda, S. Yamamura, Y. Nakatsuji and M. Okahara, Synthesis of substituted crown ethers from oligoethylene glycols, J. Org. Chem., 1980, 45, 5355-5358; (b) S. J. Jungk, J. A. Moore and R. D. Gandour, Efficient syntesis of C-pivot lariat ethers. 2-(alkyloxymethyl)-1,4,7,10,13,16-hexaoxacyclooctadecanes, J. Org. Chem., 1983, 48, 1116-1120.

46 (a) N. Yamaguci, L. M. Hamilton and H. W. Gibson, Dendritic pseudorotaxanes, Angew. Chem., Int. Ed., 1998, 37, 3275-3279; (b) F. Camps, J. Coll and S. Ricart, Synthesis of crown-ether precocenes, J. Heterocycl. Chem., 1983, 20, 249-250; (c) G. W. Buchanan, A. Moghimi and C. I. Ratcliffe, Molecular motion in crown ethers. Application of ${ }^{13} \mathrm{C}$ and ${ }^{2} \mathrm{H}$ NMR to the study of 4-carboxybenzo-24-crown-8 ether and its KNCS complex in solution and in the solid phase, Can. J. Chem., 1996, 74, 14371446.

47 (a) P. R. Ashton, I. Baxter, S. J. Cantrill, M. C. T. Fyfe, P. T. Glink, J. F. Stoddart, A. J. P. White and D. J. Williams, Supramolecular daisy chains, Angew. Chem., Int. Ed., 1998, 37, 1294-1296; (b) F. Dietrich, L. Echegoyen, M. Gomez-
Lopez, R. Kessinger and J. F. Stoddart, The self-assembly of fullerene-containing [2]pseudorotaxanes: formation of a supramolecular $\mathrm{C}_{60}$ dimer, J. Chem. Soc., Perkin Trans. 2, 1999, 1577-1586.

48 (a) T. Newhouse and P. S. Baran, If C-H bonds could talk: selective C-H bond oxidation, Angew. Chem., Int. Ed., 2011, 50, 3362-3374; (b) S. A. Girard, T. Knauber and C.-J. Li, The cross dehydrogenative coupling of $\mathrm{Csp}^{3}-\mathrm{H}$ bonds: a versatile strategy for C-C bond formations, Angew. Chem., Int. Ed., 2014, 53, 74-100; (c) A. M. Faisca Philips and A. J. L. Pombeiro, Recent developments in transition metal-catalized cross dehydrogenative coupling reactions of ethers and thioethers, ChemCatChem, 2018, 10, 33543383; (d) A. K. Bagdi, M. Rahman, D. Bhattacherjee, G. V. Zyryanov, S. Ghosh, O. N. Chupakhin and A. Hajra, Visible light pronoted cross-dehydrogenative coupling: a decade update, Green Chem., 2020, 22, 6632-6681.

49 M. Tada and H. Hirano, Photochemistry of host-guest complex I, Photochemical reaction of alkyl aryl ketones with 18-crown-6, Tetrahedron Lett., 1978, 51, 5111-5114.

50 (a) V. I. Porkhun, L. N. Rygalov and B. D. Sviridov, Mechanism of the photolysis of 2,6-diphenyl-1,4-benzoquinone in a medium of oxygen containing heterocycles, Russ. J. Gen. Chem., 1988, 58, 2121-2124; (b) V. I. Porkhun and A. I. Rakhimov, Mechanism of the photochemical reactions of substituted benzoquinones, Russ. J. Gen. Chem., 2011, 81, 890-912.

51 (a) S. Kamijo, T. Hoshikawa and M. Inoue, Photochemically induced radical transformation of $\mathrm{C}\left(\mathrm{sp}^{3}\right)-\mathrm{H}$ bonds to $\mathrm{C}\left(\mathrm{sp}^{3}\right)-\mathrm{CN}$ bonds, Org. Lett., 2011, 13, 5928-5931; (b) T. Hoshikewa, S. Yoshioka, S. Kamijo and M. Inoue, Photoinduced direct cyanation of $\mathrm{C}\left(\mathrm{sp}^{3}\right)-\mathrm{H}$ bonds, Synthesis, 2013, 874-887.

52 T. Hoshikawa, S. Kamijo and M. Inoue, Photochemically induced radical alkynylation of $\mathrm{C}\left(\mathrm{sp}^{3}\right)-\mathrm{H}$ bonds, Org. Biomol. Chem., 2013, 11, 164-167.

53 Y. Amaoka, M. Nagatomo, M. Watanabe, K. Tao, S. Kamijo and $\mathrm{M}$. Inoue, Photochemically induced readical alkenylation of C( $\left.\mathrm{sp}^{3}\right)-\mathrm{H}$ bonds, Chem. Sci., 2014, 5, 4339-4345.

54 S. Kamijo, G. Takao, K. Kamijo, M. Hirota, K. Tao and T. Murafuji, Photo-induced substitutive introduction of the aldoxime functional group to carbon chains: a formal formylation of non-acidic $\mathrm{C}\left(\mathrm{sp}^{3}\right)-\mathrm{H}$ bonds, Angew. Chem., Int. Ed., 2016, 55, 9695-9699.

55 R. Beniazza, B. Abadie, L. Remisse, D. Jardel, D. Lastécouères and J.-M. Vincent, Light-promoted metalfree cross dehydrogenative couplings on ethers mediated by NFI: reactivity and mechanistic studies, Chem. Commun., 2017, 53, 12708-12711.

56 J. K. Bower, A. D. Cypcar, B. Henriquez, S. C. E. Stieber and C. Zhang, C( $\left.\mathrm{sp}^{3}\right)-\mathrm{H}$ fluorination with a copper(II)/(III) redox couple, J. Am. Chem. Soc., 2010, 142, 8514-8521.

57 (a) W.-H. Lin, W. I. Bailey, Jr. and R. J. Lagow, The first perfluoro crown ethers, J. Chem. Soc., Chem. Commun., 1985, 1350-1352; (b) T.-Z.- Lin, W.-H. Lin, W. D. Clark, R. J. Lagow, S. B. Larson, S. H. Simonsen, V. M. Lynch, 
J. S. Brodbelt, Si. D. Maleknia and C.-C. Liou, Synthesis and chemistry of perfluoro macrocycles, J. Am. Chem. Soc., 1994, 116, 5172-5179.

58 F. Risi, A.-M. Alstanei, E. Volanschi, M. Carles, L. Piazzala and J.-P. Aycard, Photoaddition of aliphatic ethers to 4-methyl-1,2,4-triazoline-3,5-dione: application to the synthesis of functionalized crown ethers and mechanistm, Eur. J. Org. Chem., 2000, 617-626.

59 K. De Bruycker, S. Billiet, H. A. Houck, S. Chattopadhyay, J. M. Winne and F. E. Du Prez, Triazolinediones as highly enabling synthetic tools, Chem. Rev., 2016, 116, 39193974.

60 M. D. Tzirakis and M. Orfanopoulos, photochemical addition of ethers to $\mathrm{C}_{60}$ : synthesis of the simplest [60] fullerene/crown ether conjugates, Angew. Chem., Int. Ed., 2010, 49, 5891-5893.

61 G. V. Markin, S. Y. Ketkov, M. A. Lopatin, V. A. Kuropatov, A. S. Shavyrin and A. A. Belikov, Preparation of sodium and bisarenechromium fullerides containing esters of ethylene glycol, diethyleneglycol, crown ethers, methoxyarenes, and N-ethyl-phenylbenzamide, Russ. Chem. Bull. Int. Ed., 2020, 69, 751-757.

62 J. B. Zeleconok, V. V. Orlovskij, S. S. Zlotskij and D. L. Rachmankulov, Synthesis of substituted crownethers by radical addition of 18-crown-6, J. Prakt. Chem., 1990, 5, 719-722.

63 Y. B. Zelechonok, V. V. Orlocskii, S. F. Zelechonok, S. S. Zlotskii and D. L. Rakhmankulov, Synthesis of a complexone containing 8-hydroxyquinoline and crown ether fragments, Chem. Heterocycl. Compd., 1990, 26, 121.

64 R. M. Khafizova, V. V. Orlocskii, B. I. Pantukh, S. S. Zlotskii and D. L. Rakhmankulov, Antifungal properties of alkycrown ethers based on 18-crown-6, Russ. J. Appl. Chem., 1991, 64, 211-213.

65 (a) Y. B. Zelechonok, V. V. Zorin, S. S. Zlotskii and D. L. Rakhmankulov, Homolytic alkylation of 2-methylquinoline with 18-crown-6, Chem. Heterocycl. Compd., 1985, 21, 1056; (b) Y. B. Zelechonok, L. P. Ivanova, V. V. Zorin, S. S. Zlotskii and D. L. Rakhmankulov, Homologous alkylation of aromatic bases with 1,4dioxane and its macrocyclic analogs, Dokl. Chem., 1987, 297, 494-496; (c) Y. B. Zelechonok, L. P. Ivanova, V. V. Zorin, S. A. Kotlyar, S. S. Zlotskii and D. L. Rakhmankulov, homolityc alkylation of quinaldine and quinoxaline with 18-crown-6, Chem. Heterocycl. Compd., 1988, 24, 64; (d) Y. B. Zelechonok, V. V. Zorin, M. C. Klyavlin, S. S. Zlotskii, D. L. Rakhmankulov, M. Bartok and A. Molnar, homolytic substitution of 2-methylquinoline by crown ethers, Tetrahedron Lett., 1988, 29, 5037-5038.

66 N. Okugawa, K. Moriyama and H. Togo, Introduction of ether groups onto electron-deficient nitrogen containing heteroaromatics using radical chemistry under transitionmetal-free conditions, Eur. J. Org. Chem., 2015, 4973-4981.

67 S. Liu, A. Liu, Y. Zhang and W. Wang, Direct C $\alpha$-heteroarylation of structurally diverse ethers via a mild
N-hydroxysuccinimide mediated cross-dehydrogenative coupling reaction, Chem. Sci., 2017, 8, 4044-4050.

68 J. Gong and P. L. Fuchs, Alkynylation of C-H bonds via reaction with acetylenic triflones, J. Am. Chem. Soc., 1996, 118, 4486-4487.

69 J. Xiang, W. Jiang and P. L. Fuchs, Scope and limitations of functionalized acetylenic triflones in the direct alkynylation of C-H bonds, Tetrahedron Lett., 1997, 38, 66356638.

70 P. Mobian, N. Banerji, G. Bernardinelli and J. Lacour, Towards the stereoselective synthesis of inherently chiral pseudorotaxanes, Org. Biomol. Chem., 2006, 4, 224-231.

71 A. Cygan, J. F. Biernat and H. Chadzynski, Macrocyclic polyfunctional lewis-bases .3. Electrophoretic behavior of macrocyclic ethers, Pol. J. Chem., 1979, 53, 929-933.

72 Y. Nakamura, A. Asami, T. Ogawa, S. Inokuma and J. Nishimura, Regioselective synthesis and properties of novel [60]fullerene bisadducts containing a dibenzocrown ether moiety, J. Am. Chem. Soc., 2002, 124, 4329-4335.

73 J. Otsuki, K. C. Russell and J.-M. Lehn, A bis-crown ether derivative of triaminotriazine: synthesis and behavior of the ion-selective and hydrogen bonding responsive rotamers, Bull. Chem. Soc. Jpn., 1997, 70, 671-679.

74 I. A. Stempnevskaya and A. K. Tashmukhamedova, Synthesis of derivatives of dibenzo-18-crown-6 with a chloromethyl group in the side chain, Chem. Nat. Compd., 1982, 635-636.

75 W. M. Feigenbaum and R. H. Michel, Novel polyamides from macrocyclic ethers, J. Polym. Sci., Part A-1: Polym. Chem., 1971, 9, 817-820.

76 (a) G. E. Pacey, Y. P. Wu and B. P. Bubnis, Synthesis of a lithium specific chromogenic crown ether, Synth. Commun., 1981, 11, 323-328; (b) T. Liu, C. Bao, H. Wang, Y. Lin, H. Jia and L. Zhu, Light-controlled ion channels formed by amphiphilic small molecules regulate ion conduction via cis-trans photoisomerization, Chem. Commun., 2013, 49, 10311-10313; (c) D. R. Patil, D. R. Chendam, A. G. Mulik, S. D. Jagdale, P. P. Patil and M. B. Deshmukh, Synthesis and cation recognition study of novel benzo crown ether functionalized enamine derivatives, Synth. Commun., 2015, 45, 1902-1911.

77 (a) J. D. Pike, D. T. Rosa and D. Coucouvanis, Lipophilic metal-salicylideneimine-crown ether hybrids - ditopic carriers in the facilitated transport of amphiphilic molecules across bulk liquid membranes, Eur. J. Inorg. Chem., 2001, 761-777; (b) G. J. Kirkovits, R. S. Zimmerman, M. T. Huggins, V. M. Lynch and J. L. Sessler, Synthesis, structural characterization and complexation properties of the first "crowned" dipyrrolylquinoxalines, Eur. J. Org. Chem., 2002, 3768-3778.

78 S. A. Duggan, G. Fallon, S. J. Langford, V.-L. Lau, J. F. Satchell and M. N. Paddon-Row, Crown-linked porphyrin systems, J. Org. Chem., 2001, 66, 4419-4426.

79 A. D. Grebenyuk, A. A. Andreev, I. A. Stempnevskaya, M. G. Levkovich and A. K. Tashmukhamedova, Nitration of benzo crown ethers with potassium nitrate in polypho- 
sphoric acid, Chem. Heterocycl. Compd., 2000, 36, 14491456.

80 A. S. Lyakhovenko, A. V. Aksenov and M. M. Kugutov, An original approach to the amination of crown ethers, Chem. Heterocycl. Compd., 2010, 46, 1138-1139.

81 E. M. Hyde, B. L. Shaw and I. Shepherd, Complexes of platinum metals with crown ethers containing tertiary phosphine-substituted benzo groups, J. Chem. Soc. Dalton Trans., , 1978, 1696-1705.

82 F. Wada, H. Hirayama, H. Namiki, k. Kikukawa and T. Matsuda, New application of crown ethers. II. Synthesis of 4'-formylbenzocrown ethers, Bull. Chem. Soc. Jpn., 1980, 53, 1473-1474.

83 O. P. Kryatova, A. G. Kolchinsky and E. V. Rybak-Akimova, Metal-containing ditopic receptors for molecular recognition of diammonium cations, Tetrahedron, 2003, 59, 231-239.

84 S. Shao, H. B. Gobeze, P. A. Karr and F. D'Souza, 'Twopoint" self-assembly and photoinduced electron transfer in meso-donor-carrying bis(styryl crown ether)-BODIPY-bis (alkylammonium)fullerene donor-acceptor conjugates, Chem. - Asian J., 2017, 12, 2258-2270.

85 D. Patil, D. Chandam, A. Mulik, P. Patil, S. Sankapal and M. Deshmukh, Novel dibenzo-18-crown-6 ether functionalized bis-benzimidazole derivatives: synthesis and antifungal evaluation, Res. Chem. Intermed., 2016, 42, 2449-2459.

86 S. D. Jagadale, A. D. Sawant and M. B. Deshmukh, Synthesis of dibenzothiazolyldibenzo-18-crown-6 and its applications in colorimetric recognition of palladium and as antimicrobial agent, J. Heterocycl. Chem., 2017, 54, 161164.

87 A. Shinohara, C. Pan, L. Wang and H. Shinmori, Acid-base controllable singlet oxygen generation in supramolecular porphyrin-gold nanoparticle composites tethered by rotaxane linkers, J. Porphyr. Phtalocya., 2019, 23, 1-10.

88 (a) W. W. Parish, P. E. Stott and C. W. McCausland, Modified crown ether catalysts. 1. Synthesis of alkanoyl-, aroyl-, and $\alpha$-hydroxyalkylbenzo crown ethers, J. Org. Chem., 1978, 43, 4577-4581; (b) P. E. Stott and J. S. Bradshaw, Modified crown ether catalysts. 2. Synthesis of alkanoyl-, aroyl-, $\alpha$-hydroxyalkylbenzo and alkylbenzo and alkylcyclohexano crown ethers, J. Org. Chem., 1980, 45, 4716-4720.

89 (a) H. Hirano, K. Kuruyama and M. Tada, The photochemistry of the host-guest complex. V. The effect of the sodium ion on the photoreaction of benzil derivatives with a crown ether moiety, Bull. Chem. Soc. Jpn., 1981, 54, 2708-2711; (b) D. Vazquez-Garcia, A. Fernandez, M. Lopez-Torres, A. Rodriguez, A. Varela, M. T. Pereira, J. M. Vila and J. J. Fernandez, Functionalized palladacycles with crown ether rings derived from terdentate [C, $\mathrm{N}, \mathrm{N}]$ ligands. Crystal and molecular structure of the dinuclear palladium/silver complex $\left[\mathrm{Pd}\left\{3,4-\left(\mathrm{AgC}_{10} \mathrm{H}_{20} \mathrm{O}_{6}\right)\right.\right.$ $\left.\left.\mathrm{C}_{6} \mathrm{H}_{2} \mathrm{C}(\mathrm{Me})=\mathrm{NN}(\mathrm{H})\left(4^{\prime}-\mathrm{ClC}_{4} \mathrm{H}_{2} \mathrm{~N}_{2}\right)\right\}\left(\mathrm{PPh}_{3}\right)\right]\left[\mathrm{CF}_{3} \mathrm{SO}_{3}\right]_{2}$, Organometallics, 2011, 30, 396-404; (c) C. Zhang, J. Pu, H. Wu, S. Cheng, R. Zhang, A. Zhang and M. Zhang, The synthesis and mesophases studies of a novel discotic compound containing two triphenylene cores linked by crown ether, Mol. Cryst. Liq. Cryst., 2011, 542, 99-105.

90 N. Z. Saifullina and A. K. Tashmukhamedova, Acylation of dibenzo-18-crown- 6 with alkali-metal acetates in polyphosphoric acid, Chem. Heterocycl. Compd., 2001, 41, 973976.

91 A. G. Talma, H. van Vossen, E. J. R. Sudholter, J. van Eerden and D. N. Reinhoudt, Synthesis of 4'-vinylbenzo3n-crown-n ethers $(4 \leq \mathrm{n} \leq 10)$, Synthesis, 1986, 680-683.

92 (a) F. Wada, R. Arata, T. Goto, K. Kikuyawa and T. Matsuda, New application of crown ethers. III. Synthesis of 4'-hydroxy-benzocrown ethers and their bis (benzocrown ether)s linked by poy(oxyethylene) chain, Bull. Chem. Soc. Jpn., 1980, 53, 2061-2063; (b) L. Zhao, X. Cheng, F. Guo, B. Gou, C. Yang and W. Xia, Luminescent properties and logic nature of a crown Schiff base responding to sodium ion and zinc ion, J. Lumin., 2014, 145, 486-491.

93 K. Ver Heyen, E. Cielen, A. Tahri, A. Saleh, N. Boens and G. J. Hoornaert, Synthesis and characterization of new fluorescent $\mathrm{Na}^{+}$and $\mathrm{K}^{+}$indicators, Tetrahedron, 1999, 55, 5207-5226.

94 (a) A. K. Tashmukhamedova, I. A. Stempnevskaya, N. Z. Saifullina and M. G. Levkovich, Alkylation of benzoand dibenzocrown ethers by various alcohols, Chem. Heterocycl. Compd., 1986, 22, 1461; (b) E. Luboch, A. Cygan and J. F. Biernat, The synthesis of some aromatic crown ether derivatives and their ion-selective electrode properties, Tetrahedron, 1990, 46, 2461-2472.

95 S. A. Kotlyar and E. I. Klimova, Alkylation of benzocrown ethers by certain alcohols, Chem. Heterocycl. Compd., 1990, 26, 1313-1314.

96 T. Sasaki, S. Umentani, M. Masui, S. Tsurubou, T. Kimura and Z. Yoshida, Complex formation of lanthanide ions with sulfonated crown ethers in aqueous solution, Bull. Chem. Soc. Jpn., 1998, 71, 371-377.

97 D. J. Hoffart, J. Tiburcio, A. de la Torre, L. K. Knight and S. J. Loeb, Cooperative ion-ion interactions in the formation of interpenetrated molecules, Angew. Chem., Int. Ed., 2008, 47, 97-101.

98 A. D. Grebenyuk, L. V. Zotova and A. K. Tashmukhamedova, Sulfonation of benzocrown ethers by potassium sulfate in polyphosphoric acid, Chem. Heterocycl. Compd., 2001, 37, 822-826.

99 Y. Sun, X. Lu, R. Wang, L. Shi and B. Yang, Short and efficient synthesis of thiol group functionalized crown ethers, Synth. Commun., 2007, 37, 2995-3002.

$100(a) \quad$ L. N. Markovskii, D. M. Rudkevich and V. I. Kal'chenko, Chlorosulfonyl derivatives of monobenzo- and dibenzo-crown ethers, Russ. J. Org. Chem., 1989, 25, 1995-2000; (b) M. D. Barboiou, N. D. Hovnanian, C. Luca and L. Cot, Functionalized derivatives of benzocrown-ethers, $\mathrm{V}$ multiple molecular recognition of zwitterionic phenylalanine, Tetrahedron, 1999, 55, 9221-9232. 
101 R. P. Sijbesma and R. J. Nolte, Synthesis of concave receptors derived from diphenylglycoluril, Recl. Trav. Chim. Pays-Bas, 1993, 112, 643-647.

102 T. Y. Bogashenko, A. Y. Lyapunov, L. S. Kikot, A. V. Mazepa, M. M. Botoshansky, M. S. Fornari and T. I. Kirichenko, Synthesis, crystal structure, and alkali metal picrate extrac- tion capabilities of molecular clips based on diphenylglycouril and benzocrown ethes, Tetrahedron, 2012, 4757-4764.

103 E. B. Gorbunov, G. L. Rusinov, E. N. Ulomsky, V. L. Rusinov, V. N. Charusin and O. N. Chupakhin, C-H functionalization of triazolo $[\alpha]$-annulated 8-azapurines, Tetrahedron Lett., 2016, 57, 2303-2305. 